\title{
Design of and initial results from a Highly Instrumented Reactor for Atmospheric Chemistry (HIRAC)
}

\author{
D. R. Glowacki ${ }^{1}$, A. Goddard ${ }^{1}$, K. Hemavibool ${ }^{1}$, T. L. Malkin ${ }^{1}$, R. Commane ${ }^{1}$, F. Anderson ${ }^{1}$, W. J. Bloss ${ }^{1, *}$, \\ D. E. Heard ${ }^{1}$, T. Ingham ${ }^{1}$, M. J. Pilling ${ }^{1}$, and P. W. Seakins ${ }^{1}$ \\ ${ }^{1}$ School of Chemistry, University of Leeds, Leeds LS2 9JT, UK \\ *now at: School of Geography, Earth and Environmental Sciences, University of Birmingham, Egbaston, Birmingham B15 \\ 2TT, UK
}

Received: 4 July 2007 - Published in Atmos. Chem. Phys. Discuss.: 24 July 2007

Revised: 28 September 2007 - Accepted: 10 October 2007 - Published: 17 October 2007

\begin{abstract}
The design of a Highly Instrumented Reactor for Atmospheric Chemistry (HIRAC) is described and initial results obtained from HIRAC are presented. The ability of HIRAC to perform in-situ laser-induced fluorescence detection of $\mathrm{OH}$ and $\mathrm{HO}_{2}$ radicals with the Fluorescence Assay by Gas Expansion (FAGE) technique establishes it as internationally unique for a chamber of its size and pressure/temperature variable capabilities. In addition to the FAGE technique, HIRAC features a suite of analytical instrumentation, including: a multipass FTIR system; a conventional gas chromatography (GC) instrument and a GC instrument for formaldehyde detection; $\mathrm{NO} / \mathrm{NO}_{2}, \mathrm{CO}, \mathrm{O}_{3}$, and $\mathrm{H}_{2} \mathrm{O}$ vapour analysers. Ray tracing simulations and $\mathrm{NO}_{2}$ actinometry have been utilized to develop a detailed model of the radiation field within HIRAC. Comparisons between the analysers and the FTIR coupled to HIRAC have been performed, and HIRAC has also been used to investigate pressure dependent kinetics of the chlorine atom reaction with ethene and the reaction of $\mathrm{O}_{3}$ and $\mathrm{t}$-2-butene. The results obtained are in good agreement with literature recommendations and Master Chemical Mechanism predictions. HIRAC thereby offers a highly instrumented platform with the potential for: (1) high precision kinetics investigations over a range of atmospheric conditions; (2) detailed mechanism development, significantly enhanced according to its capability for measuring radicals; and (3) field instrument intercomparison, calibration, development, and investigations of instrument response at a range of atmospheric conditions.
\end{abstract}

Correspondence to: P. W. Seakins

(p.w.seakins@leeds.ac.uk)

\section{Introduction}

Volatile Organic Compounds (VOC) are emitted in substantial quantities from both biogenic and anthropogenic sources, and have a major influence on the chemistry of the troposphere. In the past few decades, much effort has been devoted to developing detailed tropospheric VOC oxidation schemes (Seinfeld, 2004); however, mechanism development is complicated because each VOC emitted into the atmosphere has a different oxidation scheme (Saunders et al., 2003). The development of accurate VOC oxidation mechanisms is essential for understanding and predicting air quality and climate change, setting emissions policies, and understanding related effects on human health. VOC oxidation schemes enable understanding and prediction of the budgets of species such as $\mathrm{O}_{3}$, which is: (1) a significant greenhouse gas (2) a species that can modify $\mathrm{OH}$ budgets thereby affecting other greenhouse gases such as $\mathrm{CH}_{4}$ (Denman and Brasseur, 2007; Forster and Ramaswamy, 2007; Ravishankara, 2005); and (3) a respiratory irritant that can impact human health in photochemical smog episodes. VOC oxidation schemes are also necessary to understand the important role that oxygenated organics, formed in gas phase oxidation processes, play in secondary aerosol formation (Baltensperger et al., 2005).

The development, testing, and refining of reliable VOC oxidation schemes involves an interplay between field campaigns, laboratory kinetics studies, and chamber measurements. Field measurements are critical to an understanding of tropospheric chemistry; however, field campaign data contain the largest degree of complexity for testing the chemistry in VOC oxidation mechanisms because of the difficulty in controlling and describing variables that affect (but

Published by Copernicus Publications on behalf of the European Geosciences Union. 
are not easily isolated from) the chemistry, such as nonhomogeneous distribution of VOCs, emissions inventories, meteorological transport processes, nonhomogenous radiation, and weather. On the other hand, laboratory kinetics studies, increasingly aided by the tools of quantum chemistry and modern rate theories, allow the most thorough study of elementary reactions (Miller et al., 2005). Such investigations provide direct and detailed information (e.g., pressure and temperature dependence of rate coefficients, product yields, and branching ratios) for the consituent reactions that are the basis of VOC oxidation schemes, and serve as a guide for the development and validation of structure activity relationships (Kwok and Atkinson, 1995). However, these studies are ideally limited to a single reaction sequence under conditions and time scales that minimize the effect of secondary chemistry, which is generally not the case in the atmosphere. Furthermore, the structural prerequisites of the apparatus used to carry out these types of studies often limits the suite of analytical instrumentation that may be coupled to the reaction volume.

Photochemical smog and environmental chamber studies mediate between field campaigns and laboratory studies (Bloss et al., 2005a; Carter, 2002; Dodge, 2000) in two ways. First, chambers allow more control of variables than is possible in field campaigns, reducing uncertainty in the direct development, validation, and testing of VOC oxidation mechanisms. Because the uncertainties pertinent to field campaigns are reduced in chambers, they offer an experimental apparatus in which to investigate how the uncertainties associated with individual rate coefficients affect a mechanism's ability to describe the oxidation of a particular VOC (Zador et al., 2005), further reinforcing the interplay between atmospheric field measurements and laboratory experiments in formulating VOC oxidation mechanisms. Secondly, with respect to laboratory kinetics experiments, chambers offer the potential for a highly instrumented test bed that may be used to perform longer time scale kinetics experiments on a wider range of compounds under more atmospherically relevant conditions, providing rate coefficients and branching ratios for use in VOC oxidation mechanisms. Chamber kinetics investigations are usually relative rate type measurements which do not require measurement of the radicals (Wallington and Nielsen, 1999; Brauers and Finlayson-Pitts, 1997).

However, in both of these applications, chambers suffer limitations because: (1) their instrumentation often necessitates investigating trace gas chemistry at concentrations higher than ambient, limiting the utility of the data and the range of conditions under which VOC oxidation mechanisms may be evaluated (Carter et al., 2005); and (2) background reactions that may affect the gas phase chemistry can be difficult to characterize, introducing uncertainty into the data (Carter et al., 2005; Dodge, 2000). Nevertheless, chambers are valuable tools for complementing and mediating between field campaigns and laboratory kinetics experiments. The European environmental chamber network (EU-
ROCHAMP: http://www.eurochamp.org/) includes 25 environmental chambers, each of which is slightly different, but which may be broadly schematized according to the following interrelated features: (1) the type of radiation used to initiate the chemistry (i.e., lamps or solar radiation), (2) the material out of which the chamber is constructed, and (3) whether the instrumentation coupled to the chamber is intended primarily to investigate gas phase chemistry or heterogeneous aerosol chemistry.

The radiation sources utilized in photochemical reactors represent a significant source of uncertainty in testing VOC oxidation mechanisms (Dodge, 2000). In the case of reactors that have artificial radiation sources, the uncertainties primarily concern characterizing the spatial and time dependent heterogeneity of the radiation field within the chamber, and the fact that not all the action spectra (i.e., the product of the cross section, quantum yield, and radiation flux as a function of wavelength) of atmospherically relevant photolysis mechanisms are well known. Using solar radiation reduces the uncertainty that arises from parameterizing action spectra for non-solar radiation sources, but introduces uncertainty regarding characterization of the homogeneity of the radiation within the chamber due to cloud effects and shadow effects that depend on solar zenith angle (Bohn and Zilken, 2005; Bohn et al., 2005). Outdoor chambers such as that at the University of North Carolina (UNC) (Dodge, 2000), EUPHORE (the European Photoreactor) (Becker, 1996), and SAPHIR (Simulation of Atmospheric PHotochemistry In a large Reaction chamber) (Wahner, 2002) are constructed from teflon, which transmits solar radiation. The very large size of such reactors enables low surface/volume $(\mathrm{S} / \mathrm{V})$ ratios, minimizing the effect of heterogeneous surface chemistry and chamber background effects. While EUPHORE, SAPHIR, and the UNC facilities are among the largest chambers in the world, teflon chambers that utilize artificial light sources have also been constructed and described in the literature (Carter et al., 2005; Thuener et al., 2004). However, teflon walls restrict chamber operation to ambient pressures and temperatures.

Cylindrical chambers constructed out of pyrex or quartz featuring radiation from an artificial light source that is transmitted through the reaction vessel allow for pressure variable experiments (Doussin et al., 1997; Barnes et al., 1994; Nolting et al., 1988; Wallington and Japar, 1989). These chambers may also be evacuated between experiments for cleaning. Constructing a chamber in which temperature variable experiments are possible is simplified if the skin is metal, and such chambers constructed of stainless steel have previously been described in the literature (Shetter et al., 1987; Akimoto et al., 1979; Stone, 1990; Tyndall et al., 1997) despite the design challenges involved in coupling a radiation source to a metal reactor in a manner that maintains a reasonably homogeneous radiation field.

This paper describes the design of and initial results from the HIRAC chamber recently constructed at the University of Leeds. HIRAC is designed to complement research at 

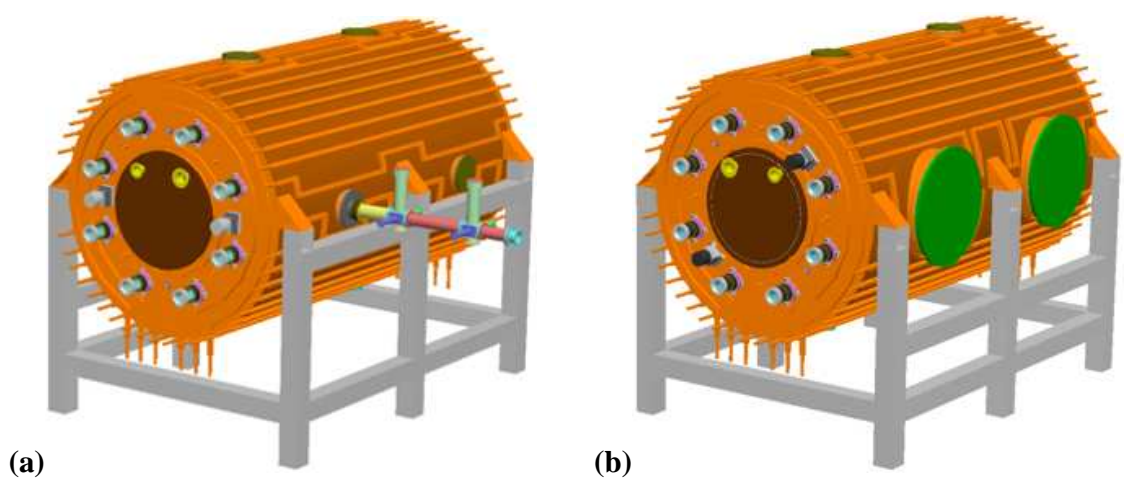

(a)

(b)
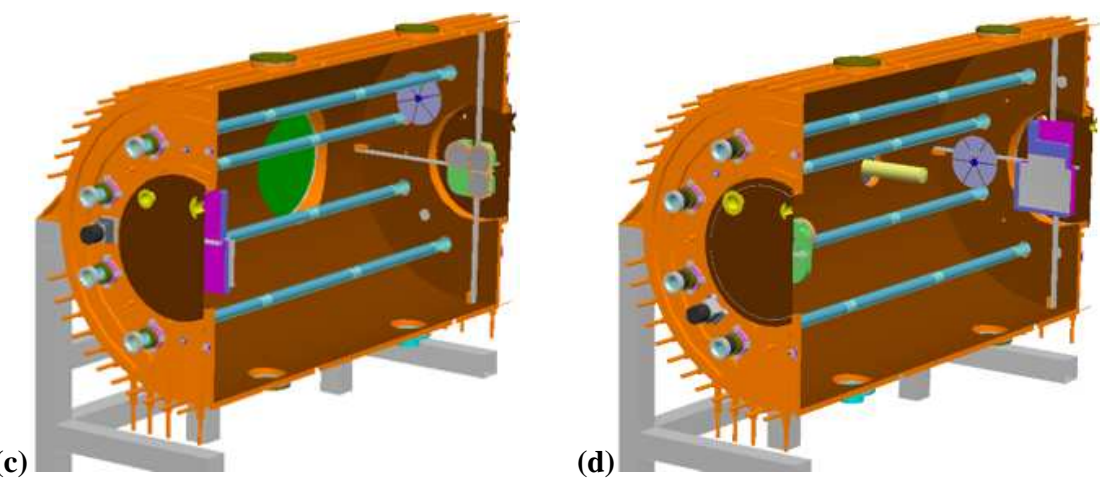

Fig. 1. (a) and (b) SolidWorks 2004 views of HIRAC, coupled to the FAGE instrument, in its support frame; (c) and (d) SolidWorks 2004 cutaway views of HIRAC, revealing its interior. In panels (c) and (d) the crosses on which the optics are mounted as well as the fans are visible. In panels (a) and (d), the FAGE instrument may be observed.

Leeds in field work (Sommariva et al., 2007) and experimental and theoretical studies of elementary reactions relevant to the chemistry of earth's atmosphere, planetary atmospheres, and combustion (Gannon et al., 2007; McKee et al., 2007; Baeza-Romero et al., 2007). In addition, the University of Leeds has been involved of the development and maintenance of the Master Chemical Mechanism (MCM), a near explicit mechanism that describes the tropospheric oxidation of 135 different VOCs (Jenkin et al., 2003; Saunders et al., 2003). HIRAC therefore offers a highly instrumented link between the various elements of the diverse atmospheric chemistry research activity at Leeds. It offers (1) a potential test bed for calibration of atmospheric field instruments, enabling more accurate measurements, which are central to an improved understanding of tropospheric oxidation mechanisms; (2) a facility that may be used to test, evaluate, and refine the MCM, with the potential for suggesting further laboratory kinetics experiments necessary to improving the mechanism; (3) a facility for kinetics investigations not possible in the laboratory, and the ability to carry these studies out at variable temperatures and pressures spanning a range of tropospheric and stratospheric conditions.

HIRAC has the potential to carry out temperature and pressure variable experiments, and the extensive suite of instru- mentation coupled to it offer a range of analytical techniques available for investigating a number of systems. Especially significant in this regard is the coupling of laser-induced fluorescence (LIF) detection to HIRAC via the Fluorescence Assay by Gas Expansion (FAGE). Many chamber studies measure radicals indirectly via VOC scavengers; however, Carter (2002) points out that significant uncertainty remains in the chamber $\mathrm{HO}_{\mathrm{x}}$ budgets predicted by current photochemical mechanisms, and many workers have found large discrepancies between $\mathrm{HO}_{\mathrm{x}}$ predicted in models and $\mathrm{HO}_{\mathrm{x}}$ observed experimentally (Bloss et al., 2005a, b). Uncertainties pertaining to heterogeneous wall chemistry, unspecified radical sources, and characterization of the radiation field within the chamber have been proposed in order to address these discrepancies; however, the facility for direct $\mathrm{HO}_{\mathrm{x}}$ measurements at very low concentrations significantly enhances the possibility for investigating these explanations.

\section{The reaction chamber}

\subsection{Description and specifications}

HIRAC was constructed from grade 304 stainless steel instead of glass to allow for mounting/access holes and 
numerous instrumentation ports to be easily cut into the skin during manufacture. Furthermore, stainless steel allowed tubes to be welded to the chamber skin in order to circulate heating and cooling fluid (see Fig. 1) and give this chamber the facility for performing temperature variable experiments over the typical temperature ranges of commercial chiller/heater systems, although this has yet to be implemented. HIRAC's design differs from other temperature and pressure variable chambers constructed from stainless steel found in the literature. Shetter et al. (1987) describe a cylindrical chamber that has a triple jacketed design, with two concentric cylinders external to the reaction volume. The compartment in contact with the skin of the reaction volume contains the heating/cooling fluid, and the outermost compartment operates as an evacuated dewar to insulate the chamber from ambient temperature. The chamber is coupled to instruments and a xenon arc photolysis light source via connecting bellows that traverse the triple jacketed design. Akimoto et al. (1979) describe a double jacketed design wherein the chamber is surrounded with a volume that contains the heating/cooling fluid, and the entire chamber is located in a thermal enclosure that insulates it. The optics are coupled to the chamber via feedthroughs that traverse the double jacketed design. In both of these chambers, photolysis light is provided from xenon arc lamps that shine through windows at the end of the chamber. The HIRAC design more closely resembles that described by Stone (1990), wherein the heating and cooling is via tubes welded to the surface of the chamber. However, the dark chamber described by Stone (1990) does not have a photolysis light source, and this significantly complicates design considerations.

Some different perspectives of the solid model constructed during the HIRAC design phase using SolidWorks 2004 (http://www.solidworks.com/) are shown in Fig. 1. HIRAC is a cylinder with internal dimensions of $2.0 \mathrm{~m}$ long and $1.2 \mathrm{~m}$ in diameter, giving an internal surface area of $\sim 10 \mathrm{~m}^{2}$ and a volume of $\sim 2.250 \mathrm{~m}^{3}$. Other internal surfaces in the chamber (lamp tubes, mirrors, and fans, which are discussed below) add $\sim 3 \mathrm{~m}^{2}$ surface area, for a $\mathrm{S} / \mathrm{V}$ of $\sim 5.8 \mathrm{~m}^{-1}$. HIRAC is mounted on a stainless steel frame (shown in Fig. 1) that rests on neoprene and cork pads to damp vibrations that otherwise affect the performance of the optical system. The curved walls of the cylinder are $4 \mathrm{~mm}$ thick and the end faces are $25 \mathrm{~mm}$ thick. A large ISO-K500 access flange is mounted in the centre of each end plate, and two more are located on one side of the cylindrical face. As shown in Fig. 1, there are a total of 6 more ISO-K160 access flanges on HIRAC's cylindrical face: two on the top, two on the bottom and two opposite the large ISO-K500 flanges. All of these flanges allow connection of different sampling ports and measurement devices such as thermocouples, pressure gauges and pumps. In addition to the flanges discussed above and shown in Fig. 1, HIRAC has eight ISO-KF16 ports, arranged with four on either end plate of the chamber. These ports allow connections for pressure gauges (Leybold Ceravac CTR90 (0-100 Torr),
Leybold Thermovac TTR91 (Pirani type gauge)), the bath gas inlet, and additional positions for gas injection and sampling. All of the $\mathrm{O}$ ring seals for the above ports are viton.

HIRAC may be pumped from ambient pressure to $\sim 2.5 \times 10^{-3}$ mbar within $\sim 70$ min using a rotary pump (Leybold Trivac D40B) backed roots blower (Leybold Ruvac WAU251) with a charcoal filled catchpot (BOC Edwards, ITC300) trap to avoid oil backflush into the evacuated chamber. The pumps are connected to one of the ISO-K160 flanges on the underside of the chamber via a gate valve. This capability allows for partial cleaning of the chamber between experimental runs.

In order to assure good mixing of gases, HIRAC has four circulation fans, with two mounted on each end plate. The fans are made from aluminium, $225 \mathrm{~mm}$ in diameter, and coupled to externally mounted variable speed DC motors via ferro fluidic feedthroughs (Ferrotec SS-250-SLBD). A flexible coupling between the motors and the feedthroughs, in conjunction with the neoprene pads between the motorhousing and the end plates leads to significant reduction in vibrations, which gives improved signal to noise ratios $(S / N)$ in the spectra obtained by the FTIR optical system (which is described below).

A thorough set of measurements were performed to investigate mixing times in HIRAC. Mixing time was defined as $\tau_{95}$, the time required for the concentration of a stable species to reach $95 \%$ of its maximum value (Pinelli et al., 2001). NO in $\mathrm{N}_{2}$ was measured with a commercial $\mathrm{NO} / \mathrm{NO}_{2}$ analyser (discussed below), and several combinations of injection and sampling points across the chamber were investigated with respect to the number of fans running as well as the speed at which the fans were run. Mixing measurements were insensitive to the particular locations of the injection and sampling points. Furthermore, the measurements indicate that at lower fan speeds $(<1500 \mathrm{rpm})$, mixing time is reduced significantly by running all of the fans. At higher fan speeds, mixing time is insensitive to the number of fans that are running. With all fans running at $1500 \mathrm{rpm}$ and $3000 \mathrm{rpm}$ (100\%), mixing times are $\sim 70 \mathrm{~s}$ and $\sim 60 \mathrm{~s}$, respectively, and show good reproducibility.

\subsection{Radiation source}

\subsubsection{Lamps}

Light for photochemical studies is provided by 24 TLK40W/05 actinic UV blacklamps (output spectrum shown in Fig. 2) housed in 8 quartz tubes (3 lamps, $\sim 60 \mathrm{~cm}$ in length, orientated end to end in each tube) that are situated radially inside of the reactive volume. Each lamp is mounted in the quartz tube via nylon collars that are attached at each end of the lamp with three grub screws. Each of the collars has three radially situated contact points with the quartz tube to maintain the lamp in the centre of the tube. This method of mounting the lamps in the tubes: (1) ensures that 
air may flow past the lamps, (2) allows wiring to be run through the tubes in order to supply the lamps with power, and (3) permits thermocouples to be placed at arbitrary locations within in each of the tubes for monitoring temperature inside of the tubes (the reasons for which are discussed below). The quartz tubes are $2300 \mathrm{~mm}$ in length, with an outside diameter of $50 \mathrm{~mm}$ and a $2 \mathrm{~mm}$ wall thickness. The tubes are mounted parallel to the chamber's principal axis, equally spaced around the circumference of a circle with a diameter of $800 \mathrm{~mm}$. A vacuum tight seal is made by compressing a silicone $\mathrm{O}$ ring onto the outer face of the quartz tube. This seal also allows for small amounts of movement accompanying temperature and pressure changes that would otherwise stress the quartz.

The output of the lamps is strongly temperature dependent, and outside of a narrow range $\left(\sim 35-39^{\circ} \mathrm{C}\right)$ their performance drops off rapidly. Given that the lamps generate heat in their normal operation and considering HIRAC's facility for carrying out temperature variable experiments, the temperature inside the quartz tubes may be regulated via two variable speed fans situated at either end of each tube, which force laboratory air though the tubes to remove hot gases surrounding the lamps. The speed of these fans is computer controlled and depends on the temperature measured within each tube by a thermocouple. The hot gases forced through the tubes are directed to a fume cupboard in order that the the ambient temperature of the laboratory is not affected and to safely dispose of any ozone formed if deeper UV lamps are used.

\subsubsection{Radiation model}

One of the significant sources of uncertainty in photoreactors is adequate knowledge of the radiation field within the chamber (Carter et al., 1995). Furthermore, modelling and analysis of experimental results obtained within reaction chambers is greatly simplified if the radiation profile may be assumed homogeneous, such that Carter et al. (1995) recommend that the radiation field within a chamber have a spatial uniformity of $\pm 10 \%$ for at least $90 \%$ of the chamber volume. Because HIRAC has the facility to perform in situ $\mathrm{OH}$ and $\mathrm{HO}_{2}$ radical measurements utilizing the FAGE technique, knowledge of the homogeneity of the radiation field is important insofar as it provides information regarding the potential for radical concentration gradients across the reaction volume. The photochemical reaction chambers at the Wuppertal facilities in Germany (Barnes et al., 1994), which use blacklamps as a radiation source, report $J_{\mathrm{NO}_{2}}$ values on the order of $10^{-3} \mathrm{~s}^{-1}$, while Carter et al. (1995) recommend that an environmental reaction chamber have a light source which is able to produce $J_{\mathrm{NO}_{2}}$ values on the order of $5 \times 10^{-3} \mathrm{~s}^{-1}$. HIRAC's integrated $J_{\mathrm{NO}_{2}}$ value has been measured by following the steady state concentrations of $\mathrm{O}_{3}, \mathrm{NO}$, and $\mathrm{NO}_{2}$, upon the photolysis of $\mathrm{NO}_{2}$ in air (Wu and Niki, 1975). Using $\mathrm{NO}_{2}$ starting concentrations of $100-200 \mathrm{ppb}, \mathrm{J}_{\mathrm{NO}_{2}}$ was measured to be $(1.93 \pm 0.10) \times 10^{-3} \mathrm{~s}^{-1}$, which falls within

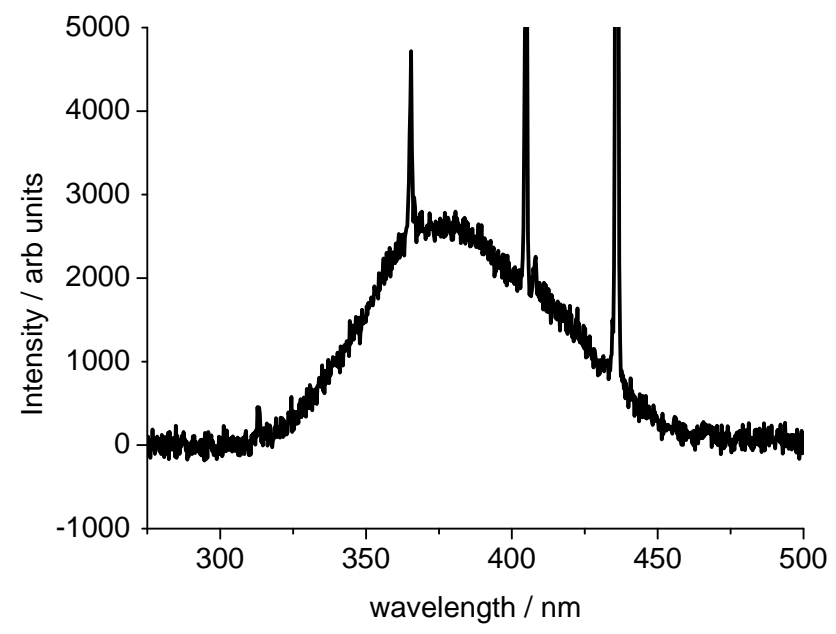

Fig. 2. Output spectrum of HIRAC's blacklamps.

the range specified by Wuppertal and Carter. An integrated $J_{\mathrm{NO}_{2}}$ photolysis rate contains no information regarding the spatial profile of the radiation field within HIRAC. Thus, a $J_{\mathrm{NO}_{2}}$ photolysis map, similar to that developed by Bohn and Zilken (2005) for the outdoor SAPHIR chamber, has been developed for HIRAC.

The $\mathrm{NO}_{2}$ photolysis frequency is the product of the temperature and wavelength dependent absorption cross section, $\sigma_{\mathrm{NO}_{2}}(\lambda, T)$, multiplied by its quantum yield, $\phi_{\mathrm{NO}_{2}}(\lambda, T)$, and the intensity of radiation at a particular wavelength and position with respect to a lamp, $F(\lambda, x) . \sigma_{\mathrm{NO}_{2}}(\lambda, T)$ and $\phi_{\mathrm{NO}_{2}}(\lambda, T)$ are well established (DeMore et al., 1997; Voigt et al., 2002), as is $F(\lambda)$ for blacklamps (Carter et al., 2005, 1995). Assuming that the wavelength dependence of the radiation passing through a small volume element located a distance $x$ away from the lamp is independent of $x, F(\lambda, x)$ may be written as $F(\lambda) F(x)$, and the $\mathrm{NO}_{2}$ photolysis frequency may be written as function of both temperature and distance from the lamp:

$J_{\mathrm{NO}_{2}}(T, x)=F(x) \int_{\lambda} \phi_{\mathrm{NO}_{2}}(\lambda, T) \sigma_{\mathrm{NO}_{2}}(\lambda, T) F(\lambda) d \lambda$

Developing an $\mathrm{NO}_{2}$ photolysis map of HIRAC thus reduces to a problem of describing the functional form of $F(\lambda) F(x)$. An analytical form of $F(\lambda) F(x)$ was derived for the case of a single tubular lamp, exploiting its cylindrical symmetry, and treating it as a line source. The position of an arbitrary point was defined in terms of $d$, the distance of the point along a line that is perpendicular to the central axis of the cylindrical lamp, and $a$, which is the distance along the lamp between two planes that are perpendicular to the lamp axis, one of which is coincident with the point of interest, and one of which is coincident with a terminus of the lamp. The equation is as follows:

$F(\lambda) F(x)=F(\lambda) F(d, a)$ 


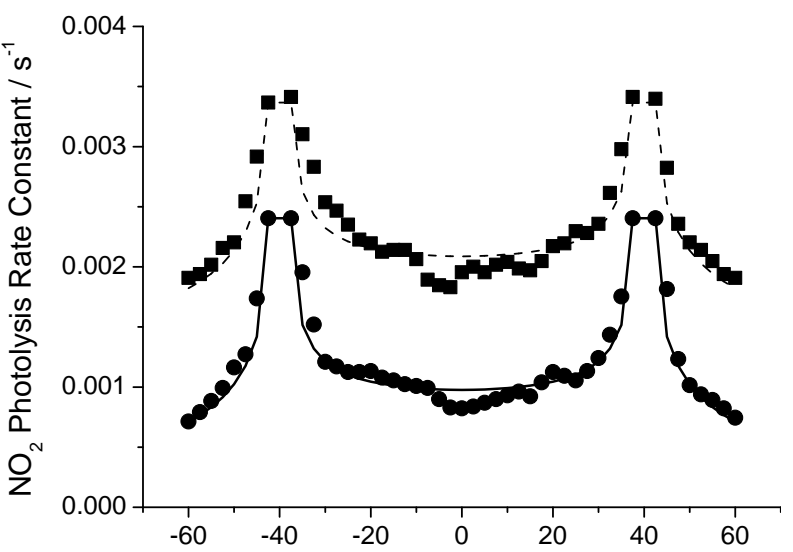

(a)

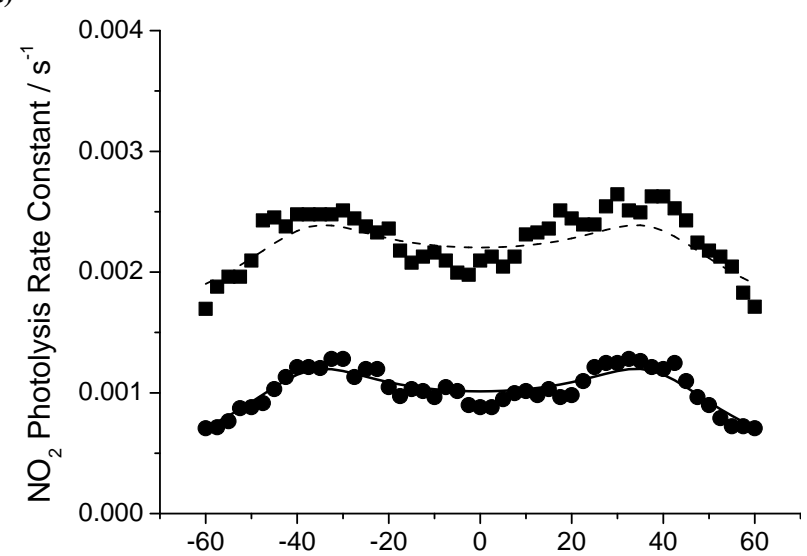

(b)

Radial Distance from Centre of HIRAC / cm

Fig. 3. Comparison of the analytical form derived to describe $\mathrm{NO}_{2}$ photolysis with the ray trace simulations for two radial transects on (a) line a and (b) line b in Fig. 4a. Two sets of data are shown for each transect: • indicates simulations that have no reflections, and - the corresponding analytical description, while $\boldsymbol{\square}$ indicates simulations using the HIRAC solid model, which includes the effect of multireflections on a surface with reflectivity of 0.55 , and -the corresponding analytical description modified to account for the effect of reflections.

$$
=\left[\frac{L_{\text {total }}(\lambda)}{2 \ell} \int_{a-2 \ell}^{a} \frac{\left(r_{\text {lamp }}+d\right)}{\left(\left(r_{\text {lamp }}+d\right)^{2}+y^{2}\right)^{3 / 2}} d y\right]
$$

where $2 \ell$ is the length of the lamp, $r_{\text {lamp }}$ is the radius of the lamp, $L_{\text {total }}(\lambda)$ represents the integrated radiance at a particular wavelength when $d \gg \ell$ (i.e., at a distance such that the lamp may be approximated as a point source), and $d y$ represents an infinitesimal "slice" of the lamp, over which the integration is carried out. Specifying that $L_{\text {total }}(\lambda) / 2 \ell=L_{S}(\lambda)$ where $L_{s}(\lambda)$ is thereby equal to the radiance per unit length of the lamp, setting $a=\ell$, and performing the integration in Eq. (2) yields the following result, which describes the light intensity at a point located on a plane that bisects the lamp:

$$
F(\lambda) F(x)=F(\lambda) F(d)=\frac{2 \ell \cdot L_{s}(\lambda)}{\left(r_{\text {lamp }}+d\right) \sqrt{\left(r_{\text {lamp }}+d\right)^{2}+\ell^{2}}}
$$

Inserting Eq. (3) into Eq. (1) gives an equation which describes the $\mathrm{NO}_{2}$ photolysis frequency as a function of the position of a point on a plane that perpendicularly bisects the lamp axis:

$$
J_{\mathrm{NO}_{2}}(T, x)=J_{\mathrm{NO}_{2}}(T, d)=\frac{2 \ell \cdot K(T)}{\left(r_{\text {lamp }}+d\right) \sqrt{\left(r_{\text {lamp }}+d\right)^{2}+\ell^{2}}}
$$

where $K$ is the hypothetical photolysis frequency at the central axis of the cylindrical lamp:

$$
K(T)=\int_{\lambda} \phi_{\mathrm{NO}_{2}}(\lambda, T) \sigma_{\mathrm{NO}_{2}}(\lambda, T) L_{S}(\lambda) d \lambda
$$

Equations (3-5) describe the plane that bisects the lamps; however, the functional form describing any plane orthogonal to the lamp axis may be described by working out the integral in Eq. (2) for different values of $a$. Unlike previous equations derived in order to describe the actinic flux from tubular lamps (Irazoqui et al., 1976), the form of $F(d)$ specified in Eq. (3) behaves as expected in the limiting cases of $d \gg \ell$ and $d \ll \ell$, going to $L_{\text {total }}(\lambda) /\left(r_{\text {lamp }}+d\right)^{2}$ (the form of a point source) and $2 L_{S}(\lambda) /\left(r_{\text {lamp }}+d\right)$ (the form of a line source), respectively.

For any integration limits, Eq. (2) may always be described as $K$ multiplied by a term that depends on the lamp dimensions and distances, as in Eqs. (4) and (5), such that determining $K$ from a single series of measurements allows $J_{\mathrm{NO}_{2}}$ to be described at any point with respect to the lamp. Furthermore, Eq. (2) is easily extended via a simple summation in order to describe $J_{\mathrm{NO}_{2}}$ as a function of position in a reactor that houses several parallel lamps oriented around the circumference of a cylinder, as in HIRAC. Figures $3 a$ and $b$ show the profiles of $J_{\mathrm{NO}_{2}}$ along two lines located on a plane that is coincident with the centre point of HIRAC, orthogonal to the cylindrical axis of symmetry with $r_{\text {lamp }}=2.0 \mathrm{~cm}$, and $K=3.20 \times 10^{-3} \mathrm{~s}^{-1}$ (the calculation of $K$ is described below). The lines represented by these figures are shown with respect to the locations of the lamps in Fig. $4 \mathrm{a}$.

In order to obtain information regarding the effect of reflections, a series of numerical optical ray trace simulations was performed with OptisWorks, which operates as a fully compatible add-in to the SolidWorks CAD software package used to design HIRAC. The simulations were carried out by propagating 10500000 rays emanating from the surfaces of the lamps, specified as Lambertian emitters in agreement with previous recommendations (Cassano et al., 1995; Irazoqui et al., 1976), and specifying that the quartz tubes have a transmission of $\sim 0.9$ in the wavelength range emitted by the lamps (Weast, 1980b). The pictorial results of a typical multireflection ray trace run are shown in Fig. 4a. 
In order to run the OptisWorks simulations, the reflection properties of stainless steel needed to be specified. Lacking more thorough data regarding the reflectivity of 304 stainless steel in the UV after an extended search, the CRC specification that $\mathrm{Fe}, \mathrm{Cr}$, and $\mathrm{Ni}$ (the main constituents of 304 stainless steel, in proportions of ca. $0.66,0.19$ and 0.10 , respectively) have reflectivities between ca. $290-$ ca. $420 \mathrm{~nm}$ of $\sim 0.54 \pm 5 \%, \sim 0.66 \pm 2 \%$, and $\sim 0.45 \pm 10 \%$, (Lide, 1994) were combined to give a net reflectivity for stainless steel of ca. 0.50 at $290 \mathrm{~nm}$ and 0.56 at $420 \mathrm{~nm}$, which is in reasonable agreement with an earlier CRC recommendation that stainless steel has a reflectivity of 0.55 at $400 \mathrm{~nm}$ (Weast, 1980a). Furthermore, a reflectance of $0.50-0.56$ is in agreement with experiments which we conducted to measure the enhancement in $J_{\mathrm{NO}_{2}}$ given a single reflecting surface, wherein a lower limit of 0.33 was obtained. The radiation profiles obtained from the OptisWorks simulations were insensitive to (1) whether the reflection of the light off of the stainless steel skin was Gaussian, Lambertian, or specular, and (2) the refractive index of the quartz tubes and the gas mixture inside of the chamber volume.

The output of an OptisWorks ray trace simulation is in Watts, and thus needs to be converted to $J_{\mathrm{NO}_{2}}$. In principle, it would be possible to convert the output in Watts to actinic flux and multiply it by the $J_{\mathrm{NO}_{2}}$ action spectrum, but this would require that the lamps in the model emit radiation over the range $300 \mathrm{~nm}-420 \mathrm{~nm}$ in a manner that mimics the lamp spectrum. The number of rays required to obtain reproducible results for such a calculation presents a computationally intractable problem. Given that the intensity maps have essentially the same relative profile regardless of the wavelength(s) at which the lamps are specified to emit, the ray trace problem was simplified and the computational expense significantly reduced by running simulations only at $\lambda=350 \mathrm{~nm}$, and specifying that stainless steel has a reflectivity of $\sim 0.53$. The error associated with this approximation over the wavelength output range of the lamps and the wavelength dependent reflectivity of stainless steel is estimated to be $<5 \%$.

A further issue that complicates numerically deriving a chamber integrated $J_{\mathrm{NO}_{2}}$ value using OptisWorks is that ray trace simulations would need to be rerun for as many planes across the chamber as required to converge $J_{\mathrm{NO}_{2}}$, which is another computationally intractable issue. However, given (1) the good agreement between the analytical model and ray trace results shown in Fig. 3 for the case with no reflection, and (2) correlation plots between the ray trace data not including reflection and that including reflection indicate that the effect of multireflections is to increase $J_{\mathrm{NO}_{2}}$ across the entire chamber by an approximately homogeneous background amount, the following strategy has been adopted: Eqs. (4) and (5) were used to evaluate $J_{\mathrm{NO}_{2}}$ for values of $K$ from $0.0025-0.0040$. For each value of $K$, the ray trace output data at $\lambda=350 \mathrm{~nm}$ could be converted to absolute $J_{\mathrm{NO}_{2}}$ values via a correlation plot. The background $J_{\mathrm{NO}_{2}}$ due to

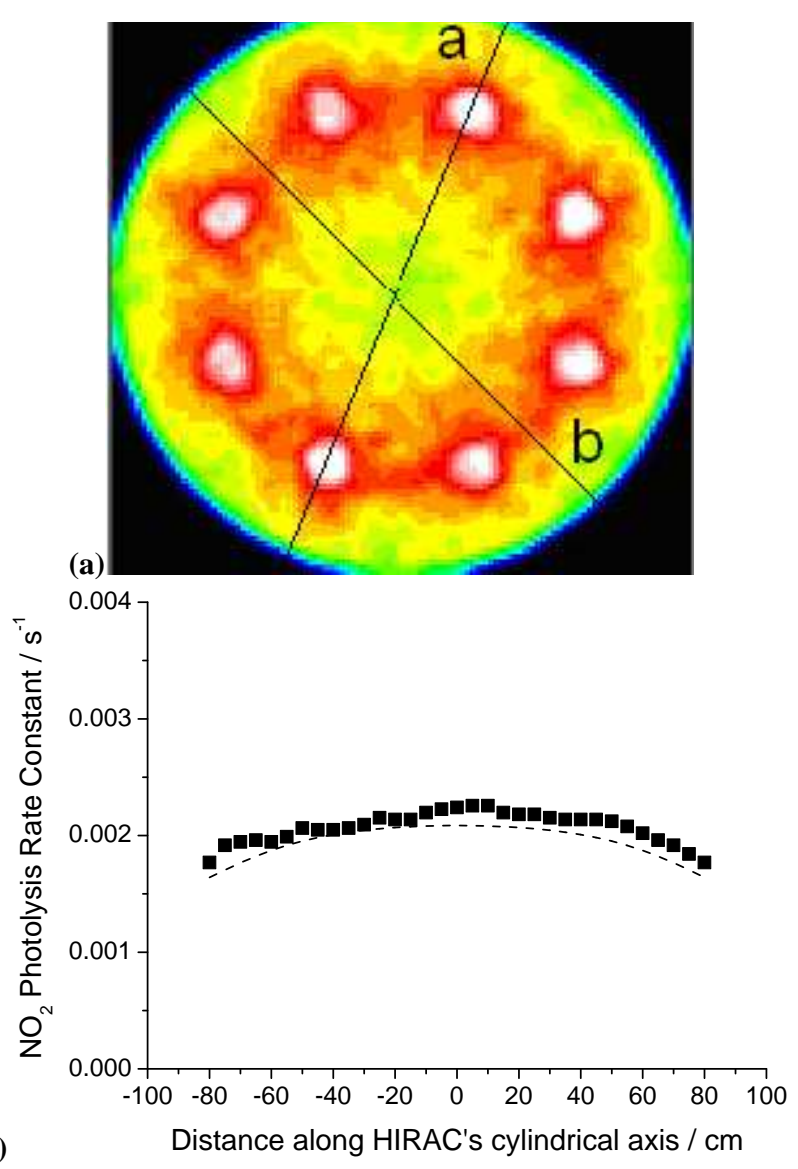

Fig. 4. (a) Pictoral results of a typical ray trace simulation, showing the relative energy incident on a plane that bisects HIRAC, and is parallel to its end flanges. The lines $\mathrm{a}$ and $\mathrm{b}$ in the figure correspond to the results plotted in Figs. 3a and b. (b) Comparison of the analytical form derived to describe $\mathrm{NO}_{2}$ photolysis as a function of position along HIRAC's cylindrical symmetry axis (--), and the multireflection ray trace results $(\boldsymbol{\square})$ carried out on the HIRAC solid model.

reflection were then calculated by comparing the ray trace curves with and without reflection (shown in Fig. 3) using another correlation plot. The value of $K$ and its corresponding $J_{\mathrm{NO}_{2}}$ due to reflection were then used in a numerical model which calculated a chamber integrated $J_{\mathrm{NO}_{2}}$ value based on $1.1 \times 10^{7}$ points uniformly distributed across HIRAC's entire volume (approximating it as a perfect cylinder). The integrated chamber $J_{\mathrm{NO}_{2}}$ from the model could then be compared to the experimental value, and the value of $K$ determined. The plots in Fig. 3 have been constructed with $K=3.20 \times 10^{-3} \mathrm{~s}^{-1}$, for which the corresponding background $J_{\mathrm{NO}_{2}}$ value due to multireflection is $1.11 \times 10^{-3} \mathrm{~s}^{-1}$. Using these values, the model gave a chamber integrated $J_{\mathrm{NO}_{2}}$ of $1.97 \times 10^{-3} \mathrm{~s}^{-1}$, in good agreement with the experimental value of $(1.93 \pm 0.10) \times 10^{-3} \mathrm{~s}^{-1}$. 


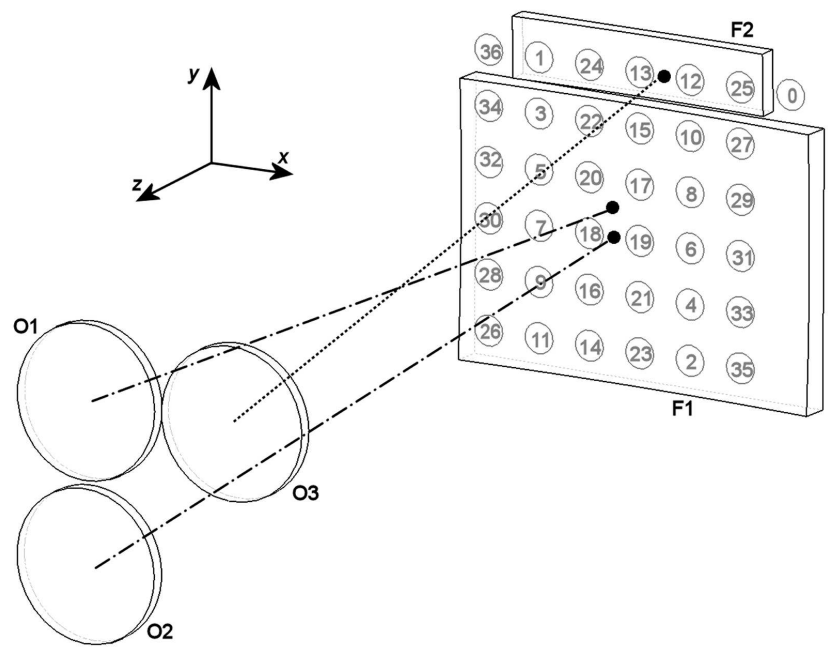

Fig. 5. Schematic of the 72 pass arrangement for the modified Chernin cell multipass optics in HIRAC. The image pattern on the field mirror is shown, as well as the location of the centre of curvature for each objective mirror. The centre of curvature F1 is located at the midpoint of the line connecting the centres of $\mathrm{O} 1$ and $\mathrm{O} 2$, while the centre of curvature of F2 is located at the midpoint of the line connecting the centres of $\mathrm{O} 1$ and $\mathrm{O} 3$.

The good agreement between the data obtained from the numerical ray trace results with and without reflection is shown alongside the corresponding analytical results in Fig. 3 (along a radial axis) and Fig. 4b (along the cylindrical axis). The ray trace data shown in these figures was obtained at the threshold of the available computing resources; however, increasing the number of rays propagated through the system would smooth these data points. The slight asymmetry in the multireflection ray trace data of Figs. 3 and 4a likely derives from the asymmetry of HIRAC's interior (e.g., one side has two large ISO-K500 access flanges, while the other side has two small ISO-K160 access flanges), for which the analytical description does not account. However, these deviations are very small with respect to $J_{\mathrm{NO}_{2}}$. The good agreement shown in these figures indicates that, given HIRAC's symmetry, it is possible to derive an analytical expression to describe $J_{\mathrm{NO}_{2}}$ as a function of position which agrees well with state of the art numerical ray trace simulations. Using this model, it has been determined that $J_{\mathrm{NO}_{2}}$ is within $\pm 15 \%$ of the average for $\sim 75 \%$ of HIRAC's volume.

\section{Instrumentation: design, specifications, and perfor- mance}

\subsection{FTIR and optics}

The FTIR and optics which couple it to HIRAC have been described in detail in a recently submitted publication by Glowacki et al. (2007). A Bruker IFS/66 FTIR spectrom- eter has been coupled via throughput matched transfer optics located in a box constantly purged by nitrogen gas to a multipass optical arrangement mounted on the interior of HIRAC. Two (8.7 millirad wedged, $\mathrm{KBr}, 75 \mathrm{~mm}$ diameter, $5 \mathrm{~mm}$ thick) windows are located on one of the end flanges, and are aligned with the cell's input and output apertures. Symmetrical transfer optics couple the multipass optics to a mid-band mercury-cadmium-telluride (MCT) detector (measurement range: $12000 \mathrm{~cm}^{-1}-600 \mathrm{~cm}^{-1}$ ), also housed in the $\mathrm{N}_{2}$ purge box. Mid IR (MIR) measurements are performed with a $\mathrm{KBr}$ beam splitter (range $7500 \mathrm{~cm}^{-1}-370 \mathrm{~cm}^{-1}$ ). The mirrors have not been mounted on the end flanges on either end of the chamber, but are instead fixed to crosses offset $10 \mathrm{~mm}$ from the internal face of the end of the chamber. The crosses are mounted in HIRAC by fastening each end of the cross beams to the cylindrical portion of the skin in order to avoid pressure dependent misalignment of the optical system that may result from the bowing of end flanges as they are subject to pressure gradients during experiments. The mirror mounts are made from aluminium with stainless steel contact points for the adjustment screws. The adjustment screws are 80 -pitch per inch with a total travel of $50 \mathrm{~mm}$. A more detailed description of the design of the the mounts is presented elsewhere (Glowacki et al., 2007).

The multipass arrangement, shown in Fig. 5, is a modified multipass matrix system (MMS) featuring three objective mirrors (Chernin, 2002; Chernin and Barskaya, 1991) that places the input and output aperture on opposite sides of the small field mirror (F2 in Fig. 5), a design that to our knowledge, has not been previously implemented. It features three objective mirrors and two field mirrors, giving a matrix of images on the field mirrors, thereby: (1) minimizing potential losses of throughput deriving from larger off axis angles implied by a traditional Bernstein-Herzberg (BH) modified White cell design (White, 1942; Bernstein and Herzberg, 1948; Tobin et al., 1996), and (2) enabling the use of a smaller field mirror for the same number of images. A number of subsequent modifications to the $\mathrm{BH}$ modified White cell design have been reported in the literature which give a matrix of images on the field mirror. In general these designs operate in a similar manner: the $\mathrm{BH}$ modified White cell, which functions as a confocal resonator, "walks" the beam through the system, giving the characteristic image arrangement on the field mirror for the first two image rows. Then, some arrangement of optics "reinjects" the beam back into the system using retroreflectors (Horn and Pimentel, 1971; Doussin et al., 1999; White, 1976) or another field mirror and another objective for every row of the image matrix (Shetter et al., 1987; Hanst, 1971). Apart from the latter technique, which requires several mirrors, the other modifications do not conserve the focal properties of the BH modified White cell. Previous ray trace simulations have shown that failure to perserve the focal properties of the BH modified White cell has non-trivial consequences for conserving optical throughput in multipass cells (Grassi 


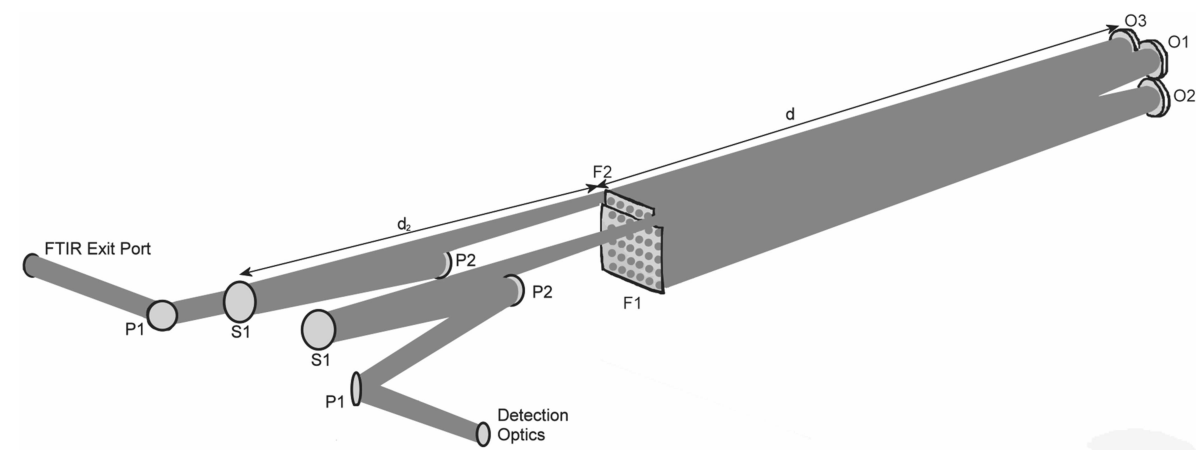

Fig. 6. Schematic of the how the throughput matched transfer optics couple the FTIR and detector optics to the multipass cell.

and Guzzi, 2001), whereas our own ray tracing simulations and measurements indicate that the three objective modified Chernin cell, which retains the focal properties of the original White cell, perfectly conserves optical throughput over a range of matrix arrangements. In practice, it is very easy to align, and shows very good stability to vibrations, with the FTIR giving good trace gas detection limits over small acquisition times even when the mixing fans, whose motor housings are located near to the optical mounts, are running.

All mirrors in the Chernin cell are made from zerodur, and have radii of curvature (ROC) of $1785 \pm 1 \mathrm{~mm}$, verified by performing a Ronchi test (Cornejo-Rodriguez, 2007) on the uncoated optics with respect to a single standard test plate. Mirror F1 has dimensions of $180 \times 255 \mathrm{~mm}$ and centre thickness of $\sim 12 \mathrm{~mm}$, mirror $\mathrm{F} 2$ has dimensions of $180 \times 45 \mathrm{~mm}$ with a centre thickness of $\sim 9 \mathrm{~mm}$, and mirrors $\mathrm{O} 1-\mathrm{O} 3$ are $100 \mathrm{~mm}$ in diameter with a centre thickness of $\sim 7.5 \mathrm{~mm}$. A schematic of the manner in which the throughput matched transfer and detection optics are coupled to the FTIR, as well as typical results of the ray trace simulations carried out with OptisWorks, is presented in Fig. 6. Transfer optics P1 and P2 are plane mirrors, $75 \mathrm{~mm}$ in diameter, and $\sim 7.5 \mathrm{~mm}$ thick, while $\mathrm{S} 1$ is $101.6 \mathrm{~mm}$ in diameter with a centre thickness of $\sim 7.5 \mathrm{~mm}$ and an ROC of $2400 \pm 12 \mathrm{~mm}$. In Fig. $6, d_{2}$, the distance between the S1 optics and the input or output apertures, is $1200 \mathrm{~mm}$. All mirrors are polished to have a maximum deviation from spherical of $\lambda / 4$ (at $633 \mathrm{~nm}$ ) with a 60/40 scratch dig ratio, and coated with protected silver.

The maximum passes through the system obtained was $124(8 \times 8$ field mirror image arrangement, $228.48 \mathrm{~m}$ total path length) with a $2.0 \mathrm{~mm}$ FTIR aperture. With a smaller aperture, it would be possible to increase this number of passes. Presently, the system has a base pathlength ( $d$ in Fig. 6) of $\sim 1.785 \mathrm{~m}$, and has been optimized at 72 passes for an aperture of $2.5 \mathrm{~mm}\left(\sim 0.13 \mathrm{~cm}^{-1}\right.$ resolution for MIR spectral regions less than $\sim 3900 \mathrm{~cm}^{-1}$ ), giving 36 images on F1 and F2 and a total pathlength of $128.52 \mathrm{~m}$. The number of passes through the system is easily varied: alignment and path length determination are undertaken by using the near infrared (NIR) output of the IFS/66 $\left(\mathrm{CaF}_{2}\right.$ beam splitter, Si diode detector, measurement range 15000 $1200 \mathrm{~cm}^{-1}$ ), which is nearly collinear with the MIR source, and which may be seen on the surface of the mirrors. Measurements of the total raw signal on the MCT detector with several different matrix arrangements, from 42 to 112 passes $(74.97 \mathrm{~m}-199.92 \mathrm{~m})$, allowed the integrated MIR $\left(7500 \mathrm{~cm}^{-1}-600 \mathrm{~cm}^{-1}\right)$ reflectivity of the mirrors to be determined as $0.98658 \pm 0.00024$, in very good agreement with the manufacturer's coating specification. The continuity of the data for these measurements indicate that the optical throughput is nearly perfectly conserved. Having measured the mirror reflectivity, determination of the optimum arrangement of 72 passes (128.5 m pathlength) is straightforward. In this arrangement, with a $2.5 \mathrm{~mm}$ aperture, the MIR beam saturates the detector. To avoid saturation, mirror P1 (situated immediately before the detector optics in Fig. 6) is very slightly misaligned in order to bring the raw signal on the detector just under the saturation threshold, allowing smaller detection limits than a smaller aperture.

The three objective MMS shows good stability to pressure variations. The alignment has been optimized for atmospheric pressures, but the raw MCT signal drops by no more than $\sim 20 \%$ at $10^{-2}$ millibar. Readjusting the transfer optics at low pressures brings the signal to within $10 \%$ of the optimized signal at atmospheric pressure. The system is very stable and has gone without realignment for several weeks with a drop in signal of no more than $\sim 15 \%$. In every case, optimum signal may then be regained by a simple readjustment of the transfer optics. For observation times as short as $60 \mathrm{~s}$ (12 scan average), detection limits (determined when $S / N=1$ ) of ozone, acetaldehyde, methane, and formaldehyde are approximately $20 \mathrm{ppbv}, 35 \mathrm{ppbv}, 30 \mathrm{ppbv}$, and 20 ppbv, respectively for the 72 pass system (total pathlength $=128.5 \mathrm{~m}$ ). The optical system is quite stable with respect to vibrations from the fans. With the fans running at $\sim 3000 \mathrm{rpm}$, fast enough to give a mixing time of $\sim 60 \mathrm{~s}$, the detection limits of ozone, acetaldehyde, methane, and formaldehyde are increased to approximately $60 \mathrm{ppb}, 80 \mathrm{ppb}$, $75 \mathrm{ppb}$, and $50 \mathrm{ppb}$, respectively. Without the fans running, the effects of vibration in this cell are negligible. 


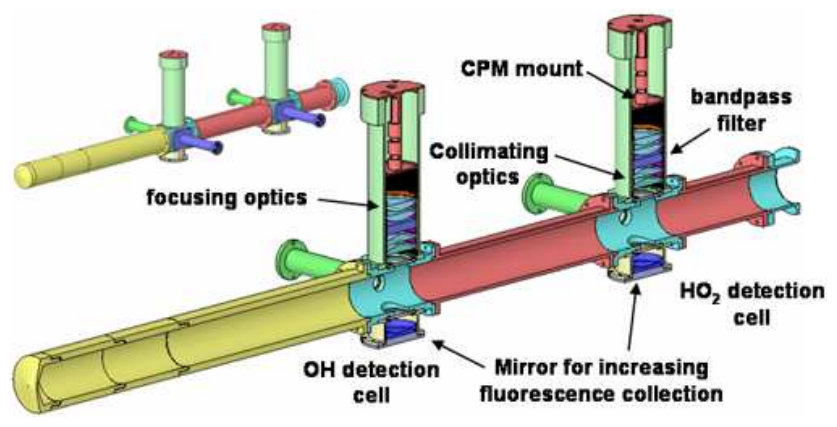

Fig. 7. SolidWorks 2004 model of the FAGE instrument which is coupled to HIRAC in Fig. 1 and corresponding cutaway view of the FAGE instrument, revealing the fluorescence chambers for $\mathrm{OH}$ and $\mathrm{HO}_{2}$ detection as well as the optics and PMT mounts for each fluorescence chamber.

\subsection{FAGE instrument}

\subsubsection{Instrument description}

A significant feature of HIRAC, distinguishing it from other chambers of its size, is the facility for carrying out absolute $\mathrm{OH}$ and $\mathrm{HO}_{2}$ in situ measurements via the FAGE technique, which has been described in recent reviews (Heard, 2006; Heard and Pilling, 2003). A SolidWorks model of the FAGE apparatus is shown in Fig. 7. A continuous sample of chamber gas undergoes supersonic expansion through a $0.8 \mathrm{~mm}$ diameter pinhole at the apex of a conical inlet, and then travels down a black anodized aluminium tube (internal diameter $50 \mathrm{~mm}$ ) into a fluorescence cell, maintained at low pressure (typically 1-2 Torr). This tube is coupled to HIRAC through a compression O-ring seal affixed to a flange which attaches to one of the ISO-K160 access ports shown in Fig. 1. The low pressure of the fluorescence cell is maintained with a rotary pump backed roots blower combination (Leybold trivac D40B and ruvac WAU251) and the flow rate through the sampling pinhole is $\sim 2 \mathrm{~L} \mathrm{~min}^{-1}$. Furthermore, the length of the tube down which the gas expansion occurs may be extended or shortened, a design permitting easy variation of the sampling pinhole's position within the chamber, which will be particularly useful for examining whether the radiation field profile within HIRAC gives rise to radical concentration gradients.

A pulsed probe laser beam is directed into the low pressure fluorescence chamber, orthogonal to the axis which the HIRAC gas sample traverses, and excites $\mathrm{OH}$ radicals through the $A^{2} \Sigma^{+}\left(v^{\prime}=0\right) \leftarrow \mathrm{X}^{2} \Pi_{i}\left(v^{\prime \prime}=0\right) \mathrm{Q}_{1}$ (Eq. 2) transition near $308 \mathrm{~nm}(307.995 \pm 0.001 \mathrm{~nm})$. On-resonance fluorescence accompanying the subsequent relaxation of the $\mathrm{OH}$ $A^{2} \Sigma^{+}$is detected on an axis orthogonal to the gas expansion and the probe beam. Precise tuning to the peak of the Q1(2) spectral line of the $\mathrm{OH}$ transition is achieved by splitting a small fraction of the light from the probe laser to a reference cell containing a relatively high $[\mathrm{OH}]$, produced by passing water vapour in ambient air at over a heated nichrome wire at $\sim 3.5$ Torr. Maintaining the fluorescence cell at low pressure (2 Torr) extends the $\mathrm{OH}$ fluorescence lifetime well beyond the duration of the laser pulse ( $35 \mathrm{~ns}$ ), enabling the much larger scattered light signal from the probe laser to be discriminated from the longer lived $\mathrm{OH}$ fluorescence signal by using delayed photon counting. The background laser scatter can be further minimized by switching the photomultiplier detector off during the laser-pulse and switching on rapidly immediately afterwards using a modification of a home-built high voltage gating circuit (Creasey et al., 1998). Use of a laser with a high pulse repetition frequency and low pulse energy avoids optical saturation and minimizes photolytic generation of $\mathrm{OH}$ from other chemical species. The latter consideration determines why on-resonant detection of the $308 \mathrm{~nm}$ excitation is used instead of the alternative off-resonant technique, wherein relaxation of the $\mathrm{OH} A^{2} \Sigma^{+}$is detected following $\mathrm{OH}$ radical excitation via the $A^{2} \Sigma^{+}\left(v^{\prime}=1\right) \leftarrow \mathrm{X}^{2} \Pi_{i}$ $\left(v^{\prime \prime}=0\right)$ transition near $282 \mathrm{~nm}$ (Heard, 2006).

$\mathrm{HO}_{2}$ detection is accomplished by adding $\mathrm{NO}$ at a flow rate of $10-50 \mathrm{sccm}$ to the flowtube via an inlet positioned $50 \mathrm{~mm}$ downstream of the $\mathrm{OH}$ fluorescence cell, but $335 \mathrm{~mm}$ upstream from a second $\mathrm{OH}$ detection cell (Fig. 7) in order to rapidly convert $\mathrm{HO}_{2}$ to $\mathrm{OH}$ via the reaction:

$\mathrm{HO}_{2}+\mathrm{NO} \rightarrow \mathrm{OH}+\mathrm{NO}_{2}$

The $\mathrm{HO}_{2}$ number density can then be obtained from the difference between the $\mathrm{OH}$ and $\mathrm{HO}_{2}$ measurements in this second cell. A known concentration of NO is added to optimize conversion of $\mathrm{OH}$ to $\mathrm{HO}_{2}$, while ensuring no back-diffusion of $\mathrm{NO}$ to the first $\mathrm{OH}$ measurement cell occurs. Potential interferences from $\mathrm{RO}_{2}$ to the FAGE detection of $\mathrm{HO}_{2}$ have been previously investigated (Ren et al., 2004), and shown to be insignificant. The conversion of $\mathrm{HO}_{2}$ to $\mathrm{OH}$ is performed in a fluorescence chamber that has a pressure of $\sim 1$ Torr. Thus, although $\mathrm{RO}_{2}$ will be converted into $\mathrm{RO}$ quite readily, the reduced pressure means that the rate of $\mathrm{RO}+\mathrm{O}_{2}$ to give $\mathrm{HO}_{2}$ is quite slow even when $\mathrm{RO}_{2}$ (and hence $\mathrm{RO}$ ) is high. The level of interference depends on the relative ratio of $\mathrm{RO}_{2}$ and $\mathrm{HO}_{2}$; however, under conditions with high $\mathrm{RO}_{2}$ concentrations, the levels of $\mathrm{HO}_{2}$ are also likely to be higher, and the effect of $\mathrm{RO}_{2}$ interference on any $\mathrm{HO}_{2}$ measurements is expected to be minor.

For the measurements of $\mathrm{OH}$ described in this paper, the HIRAC FAGE system uses a Nd:YAG pumped titanium laser system (Bloss et al., 2003) to generate $308 \mathrm{~nm}$ radiation at $5 \mathrm{kHz}$ pulse-repetition-frequency. The laser power entering each fluorescence cell is typically $5-10 \mathrm{~mW}$. As shown in Fig. 7, the fluorescence signal is collimated via two touching plano-convex $50 \mathrm{~mm}$ diameter, $100 \mathrm{~mm}$ focal length (at $633 \mathrm{~nm}$ ) lenses, passes through a $308 \mathrm{~nm}$ bandpass interference filter (Barr Associates, $308.75 \mathrm{~nm}$ central wavelength, $5.0 \mathrm{~nm}$ bandwidth, 50\% transmission), and is focused onto the electronically gated channel photomultiplier (CPM, 
C943P, Perkin Elmer) using optics identical to those used for collimation. The optics are isolated from the fluorescence chamber via an antireflection coated UV grade fused silica window. The solid angle of the $\mathrm{OH}$ fluorescence collected is approximately doubled by a concave spherical mirror located opposite the window that separates the optics and detector housing from the fluorescence chamber. Gated photon counting (Becker and Hickl, PMS MSA 300A) is used to monitor the signal from the PMT, which is subsequently normalised for laser power measured by a photodiode.

Switching the blacklamps within HIRAC on and off results in no change of PMT signal, indicating that scattered light from the chamber does not interfere with the $\mathrm{OH}$ fluorescence signal. Interferences with the measured $\mathrm{OH}$ fluorescence signal arise from scattered laser light and detector dark current (typically $<1$ count s $\mathrm{mW}^{-1}$ ). These are subtracted by performing alternating measurements on and off the $\mathrm{OH}$ spectral line in order to ascertain the background signal, which has no contribution from OH LIF.

\subsubsection{Instrument calibration}

LIF is not an absolute technique and calibration of the sensitivity of the FAGE instrument is necessary. Calibration procedures have been described in detail in previous publications (Faloona et al., 2004; Floquet, 2006) such that only a brief overview will be provided here. The signal due to $\mathrm{OH}$ fluorescence, $S_{\mathrm{OH}}$, is related to the concentration of $\mathrm{OH}$, $[\mathrm{OH}]$ by:

$S_{\mathrm{OH}}=C_{\mathrm{OH}} \times P \times[\mathrm{OH}]$

where $C_{\mathrm{OH}}$ is the instrument sensitivity (counts $\mathrm{s}^{-1} \mathrm{~mW}^{-1}$ molecule $\mathrm{cm}^{3}$ ) and $P$ is the laser power $(\mathrm{mW})$. For determining instrument sensitivity, $184.9 \mathrm{~nm}$ photolysis of water vapour at atmospheric pressure has become the standard method (Heard and Pilling 2003). Within the photolysis region, the concentration of $\mathrm{OH}$ is determined as:

$[\mathrm{OH}]=\left[\mathrm{H}_{2} \mathrm{O}\right] \sigma_{\mathrm{H}_{2} \mathrm{O}, 184.9 \mathrm{~nm}} \phi_{\mathrm{OH}, 184.9 \mathrm{~nm}} F_{184.9 \mathrm{~nm}} t$

where $\sigma_{\mathrm{H}_{2} \mathrm{O}, 184.9 \mathrm{~nm}}$ is the absorption cross-section of water vapour $\left[7.1 \pm 0.2 \times 10^{-20} \mathrm{~cm}^{-2}\right.$ (Cantrell et al., 1997), $\phi_{\mathrm{OH}}, 189.4 \mathrm{~nm}$ is the photodissociation quantum yield of $\mathrm{OH}$ $\left(\phi_{\mathrm{OH}}, 189.4 \mathrm{~nm}=1\right), F_{184.9 \mathrm{~nm}}$ is the photon flux of the lamp, and $t$ is the photolysis exposure time.

Calibration of the HIRAC FAGE instrument utilizes a "wand" system, initially developed by Faloona et al. (2004). Briefly, humidified air at atmospheric pressure is passed through a $1.27 \mathrm{~cm} \times 1.27 \mathrm{~cm}$ square internal section blackanodised aluminium tube of $30 \mathrm{~cm}$ length known as the "wand". A mercury pen-lamp is housed in a heated (36$40^{\circ} \mathrm{C}$ ) aluminium casing flushed with nitrogen and positioned over a $3.81 \mathrm{~cm}$ Suprasil ${ }^{\mathrm{TM}}$ window, mounted $2 \mathrm{~cm}$ from the end of the wand. The lamp output is collimated using a series of thin walled tubes $(3 \mathrm{~mm}$ diameter, $8 \mathrm{~mm}$ length) to create a uniform flux across the photolysis region. Immediately prior to the air entering the wand a small flow is diverted to a dew point hygrometer (CR4, Buck Research Instrument) to measure the concentration of water vapour in the flow. The product of the photon flux and the photolysis exposure time as a function of lamp current is determined using NO actinometry (Edwards et al., 2003), which allows a determination of $F_{184.9 \mathrm{~nm}}$ and $t$ according to the following relation:

$[\mathrm{NO}]=\left[\mathrm{N}_{2} \mathrm{O}\right] \sigma_{\mathrm{N}_{2} \mathrm{O}, 184.9 \mathrm{~nm}} \phi_{\mathrm{NO}, 184.9 \mathrm{~nm}} F_{184.9 \mathrm{~nm}} t$

A $5 \mathrm{slm}$ flow of $\mathrm{N}_{2} \mathrm{O}$ is added to zero air (45 slm), NO is measured with a commercial NO analyser (Thermo Electron Corporation, Model $42 \mathrm{C}$ ), $\sigma_{\mathrm{N}_{2} \mathrm{O}}, 184.9 \mathrm{~nm}$ is the absorption crosssection of $\mathrm{N}_{2} \mathrm{O}\left[1.43 \times 10^{-19} \mathrm{~cm}^{2}\right.$ molecule ${ }^{-1}$ (DeMore et al., 1997)], and $\varphi_{\mathrm{NO}}, 184.9 \mathrm{~nm}$ is the quantum yield of $\mathrm{NO}$ from $\mathrm{O}\left({ }^{1} \mathrm{D}\right)+\mathrm{N}_{2} \mathrm{O} \rightarrow 2 \mathrm{NO}$ (Edwards et al., 2003). The uncertainty for the actinometry is $\pm 13 \%(1 \sigma)$, and the total calibration uncertainty is $\pm 23 \%(1 \sigma)$.

Gas flow through the wand at $50 \mathrm{slm}$ assures a fully turbulent radial flow profile, with uniform mixing of the concentrations of $\mathrm{OH}$ produced across the face of the wand. To allow calibrations of $\mathrm{OH}$ between $\sim 2 \times 10^{6}$ and $2 \times 10^{9}$ molecule $\mathrm{cm}^{-3}$, the concentration of water vapour was maintained at $0.03 \% \mathrm{v} / \mathrm{v}$ water vapour in the calibration gas, and the photon flux varied between $5.6 \times 10^{12}$ $3.4 \times 10^{13}$ photons $\mathrm{cm}^{-2} \mathrm{~s}^{-1}$ (Lamp current $\left.=0.5-3 \mathrm{~mA}\right)$. The design of the HIRAC fluorescence cells is very similar to those used on the Leeds aircraft FAGE instrument, for which the sensitivity to $\mathrm{OH}$ and $\mathrm{HO}_{2}$ was found to be invariant over the water vapour mixing ratio range of $0.03 \%$ and $2.2 \%$. Initial results indicate that the HIRAC FAGE instrument shows a similar insensitivity to water vapor but more complete characterization of the instrument sensitivity is planned.

The limit of detection (LOD) is determined by:

$[\mathrm{OH}]_{\min }=\frac{S / N}{C_{\mathrm{OH}} \times P} \sqrt{\left(\frac{1}{m}+\frac{1}{n}\right) \frac{1}{t}} \sigma_{b}$

where: $S / N$ is the signal to noise ratio, $m$ and $n$ are the number of online and offline points, respectively, $t$ is the data collection time, and $\sigma_{b}=\sqrt{S_{l b}+S_{d c}} . \quad S_{l b}$ is the average signal due to background laser scatter and $S_{d c}$ is the average signal due to dark counts from the CPM. For a $1 \mathrm{~s}$ integration time, the limit of detection (LOD) for $\mathrm{OH}$ was calculated to be $4.7 \times 10^{5}$ molecule $\mathrm{cm}^{-3}$, where $S / N=1$, $C_{\mathrm{OH}}=9 \times 10^{-8} \mathrm{cts} \mathrm{s}^{-1} \mathrm{~mW}^{-1}$ molecule $\mathrm{cm}^{3}, \quad P=11 \mathrm{~mW}$, $m=1142$ points, $n=119$ points, $t=1 \mathrm{~s}, S_{l b}+S_{d c}=10.9 \mathrm{cts} \mathrm{s}^{-1}$.

\subsection{Gas chromatography instrumentation}

\subsubsection{Commercial GC}

In addition to the FTIR multipass optics, organic compounds may be measured in HIRAC via a commerical gas chromatography (GC) instrument (HP 6890). Detection of the 


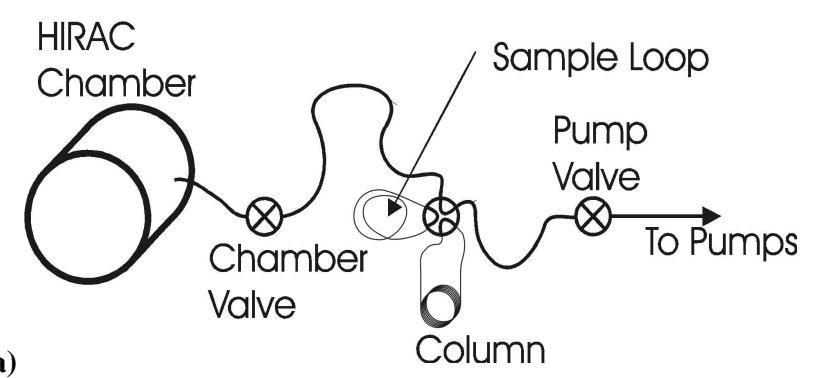

(a)

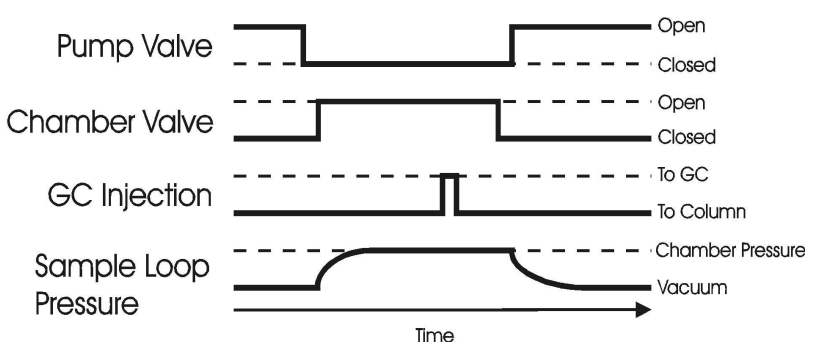

Fig. 8. (a) schematic of the automated GC sampling system coupled to HIRAC; (b) chromatograph showing the sequence of events in the automated GC sampling system.

species separated on the column is via a flame ionisation detector (FID) maintained at $250^{\circ} \mathrm{C}$. Gas samples are injected onto the column using a six way gas sampling valve equipped with a $5 \mathrm{~mL}$ stainless steel loop. Gas samples are drawn from HIRAC into the stainless steel loop using a diaphragm pump. The gas sampling valve is coupled to HIRAC via $1 / 16$ inch (i.d.) teflon tubing attached to a moveable stainless steel sampling inlet, which is fitted on an ISO-K160 flange adjacent to that housing the FAGE nozzle (shown in Fig. 1a). The GC sampling system, for which a schematic is shown in Fig. 8a, has been automated by using two solenoid valves, one of which (the pump valve) is located between the gas sampling valve and the pump, and one of which (the chamber valve) is located between the gas sampling valve and HIRAC. In normal operation, the chamber valve is closed and the pump valve opened in order to evacuate the teflon tube and the stainless steel sample loop. To fill the sample loop, the pump valve is closed and the chamber valve opened, allowing a sample of chamber gas to fill the sampling loop at the current chamber pressure. The gases in the sampling loop are transferred to the column using the six way gas sampling valve, and the chamber and pump valve are reset in order to purge the teflon line and sample loop. This entire automated sampling cycle, which lasts $\sim 120 \mathrm{~s}$, is represented as a function of time in Fig. $8 \mathrm{~b}$, and the duty cycle for typical measurements is $\sim 20 \mathrm{~h}^{-1}$. Detection limits of some species measured thus far with the commerical GC are as follows: i-butane, $0.1 \mathrm{ppm}$; ethane, $0.3 \mathrm{ppm}$; and chloroethane, $0.3 \mathrm{ppm}$.

\subsubsection{Formaldehyde GC}

The formaldehyde instrument coupled to HIRAC has been described in detail previously (Hopkins et al., 2003) and been successfully deployed in field campaigns to monitor ambient formaldehyde (Still et al., 2006). The instrument, coupled to HIRAC via teflon tubing, transfers a loop sample of 1$6 \mathrm{~mL}$ onto the column $(50 \mathrm{~m}, 0.32 \mathrm{~mm}$ id, $100 \%$ dimethyl polysiloxane, WCOT column, $5 \mu \mathrm{m}$ phase thickness, CPSil 5CB Chrompack, Netherlands) using helium carrier gas (BOC, CP grade, further purified by a helium purifier HP2, Valco Instruments) and the formaldehyde is refocused at the head of the column with liquid $\mathrm{N}_{2}$ cold trap. Following elution of the untrapped air, the analytes were released, separated in the column, and detected using an argon doped (1\% Ar in He mix, Air Products Special Gases), pulsed discharge helium ionization detector (Model D44, VICI AG, Schenkon, Switzerland). To prevent the deposition of water and heavier species on the column, the column flow is reversed and the column back flushed $\left(30 \mathrm{ml} \mathrm{min}^{-1}, 70 \mathrm{~s}\right.$, backing pressure $60 \mathrm{psi}$ ) after elution of formaldehyde. Calibration with a permeation source (Kintec, Texas) allows the relative measurements to be converted to absolute values. Samples may be obtained from HIRAC in a manner identical to that described above for the commercial GC. The formaldehyde instrument detection limit is $42 \mathrm{ppt}$, it has a duty cycle of $\sim 11 \mathrm{~h}^{-1}$.

\subsection{Other analysis instrumentation}

In addition to the instrumentation described above, HIRAC is also coupled to a suite of commerical chemical analyzers for measurement of $\mathrm{NO}, \mathrm{NO}_{2}, \mathrm{O}_{3}, \mathrm{CO}$, and $\mathrm{H}_{2} \mathrm{O}$. The analyzers are connected to any of HIRAC's several chamber sampling ports via teflon tubing. Currently the sampling position is simply located at the surface of one of the ISO-K500 flanges; however, it is possible to change the sampling position to a variable length inside the chamber by coupling it to a stainless steel tube that passes through one of the flanges fixed to a HIRAC access port, as occurs with the GC sampling.

A conventional subambient chemiluminescence analyzer is used for detection of $\mathrm{NO}$ and $\mathrm{NO}_{2}$ (Thermo Electron Corporation, Model 42C). The detection limits for each species is $400 \mathrm{ppt}$, the sample flow rate at ambient pressure is $0.6 \mathrm{~L} / \mathrm{min}$, the response time is $40 \mathrm{~s}$ with a $10 \mathrm{~s} \mathrm{av-}$ eraging time, and the instrument operates down to a pressure of $\sim 725$ mbar. A conventional UV photometric $\mathrm{O}_{3}$ Analyzer is used for $\mathrm{O}_{3}$ detection (Thermo Electron Environmental instruments, Model 49C), which has a detection limit of $1.0 \mathrm{ppb}$, a standard sample flow rate of $2 \mathrm{~L} / \mathrm{min}$, a response time of $20 \mathrm{~s}$ with a $10 \mathrm{~s}$ averaging time, and operates down to a pressure of $\sim 725$ mbar. The $\mathrm{O}_{3}$ analyser has been calibrated using a commercial ozone primary standard (Thermo Electron Corporation 49i-PS) and intercomparisons with the FTIR, discussed in the next section, are linear. CO detection is via a commercial gas chromatographic reduction 
gas analyser (Trace Analytical, Model RGA3), which has a detection limit of $10 \mathrm{ppb}$, a sample flow rate of less than $35 \mathrm{~mL} / \mathrm{min}$, a response time of $\sim 30 \mathrm{~s}$, and is capable of operating at pressures varying from vacuum to ambient. Intercomparisons of the $\mathrm{CO}$ measurements with the FTIR are also linear. $\mathrm{H}_{2} \mathrm{O}$ is monitored with an infrared hygrometer (Analytical Development Company, Model 7000), which has a detection limit of $5 \mathrm{ppm}$, a sample flow rate of $0.6 \mathrm{~L} / \mathrm{min}$, a response time of $5 \mathrm{~s}$ with a $5 \mathrm{~s}$ average time, and operates at ambient pressure. All of the data output from the analysers are monitored with a LabView program run on a laboratory PC.

\section{Initial results}

\subsection{Comparison of FTIR with commercial analysers}

Intercomparisons to investigate FTIR measurements with respect to the calibrated $\mathrm{O}_{3}$ analyser and the $\mathrm{CO}$ analyser were undertaken. The results are shown in Figs. 9a and b. In the $\mathrm{O}_{3}$ intercomparisons, a mercury pen-ray lamp was attached to a port located on the end of the chamber adjacent to the Chernin cell objective mirrors. $\mathrm{O}_{2}$, delivered by stainless steel tubing, was passed over the mercury lamp at a rate of $\sim 2 \mathrm{~L} \mathrm{~min}^{-1}$ in order to balance the sampling rate of the $\mathrm{O}_{3}$ analyser, measured with a rotameter flow meter. The mercury lamp's $184.9 \mathrm{~nm}$ emission was used to photolyse $\mathrm{O}_{2}$ to give $\mathrm{O}\left({ }^{3} \mathrm{P}\right)$, which recombines with $\mathrm{O}_{2}$ to produce $\mathrm{O}_{3}$. FTIR spectra were obtained by averaging 12 scans (measurement time $\sim 60 \mathrm{~s}$ ), and integrating the $\mathrm{O}_{3}$ absorption features with respect to the baseline from $995 \mathrm{~cm}^{-1}$ to $1072 \mathrm{~cm}^{-1}$, and $\left[\mathrm{O}_{3}\right]$ was obtained from the analyser every $20 \mathrm{~s}$. For the CO measurements, a known [CO] was transferred via the vacuum line into a $0.97 \mathrm{~L}$ stainless steel delivery vessel cleaned between experimental runs by attaching it to the vacuum line and subsequent pumping. The chamber was then evacuated to a pressure $\sim 50$ mbar below ambient, and the delivery vessel, coupled to the chamber via teflon tubing, was flushed with $\mathrm{N}_{2}$ until the pressure in the chamber was brought to ambient $\left(\sim 150 \mathrm{~L} \mathrm{~N}_{2}\right.$ at a flow rate of $\left.100 \mathrm{~L} \mathrm{~min}^{-1}\right)$. Gas samples removed from HIRAC were replenished with $\mathrm{N}_{2}$ to maintain a constant pressure. [CO] was obtained every $\sim 30$ s with the analyser, while FTIR spectra were obtained by averaging 128 scans (measurement time $\sim 4 \mathrm{~min}$ ), and the CO band areas and peak heights from $2250-2030 \mathrm{~cm}^{-1}$ were measured. Both plots indicate that FTIR measurements are linear with respect to the commercial analysers. As a check on the accuracy of the measurements obtained with the $\mathrm{O}_{3}$ analyzer and $\mathrm{CO}$ GC instrument, simulations of $\mathrm{CO}$ and $\mathrm{O}_{3}$ FTIR spectra with the HITRAN database (Rothman et al., 2005) were performed for a representative range of the CO and $\mathrm{O}_{3}$ measurements shown in Fig. 9. The simulations used the LINEPAK suite of algorithms (Gordley et al., 1994) interfaced to spectral calculation software available on the web

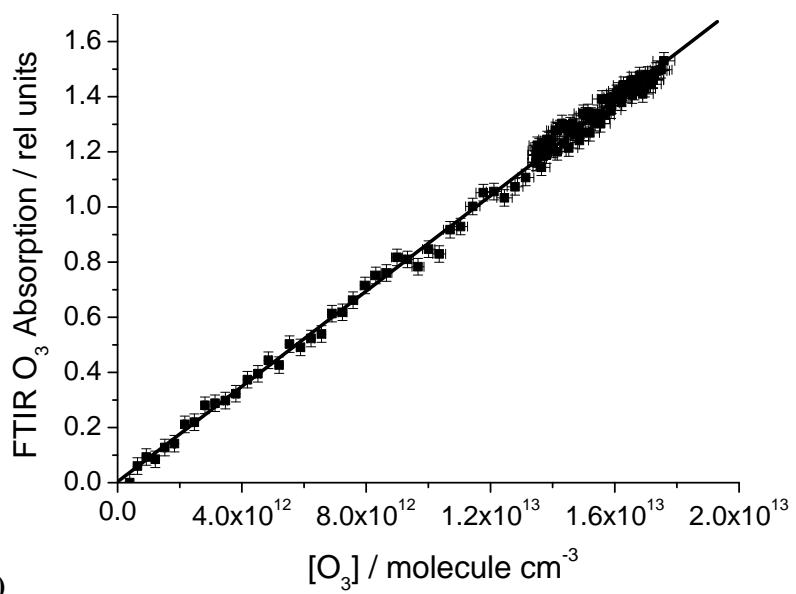

(a)

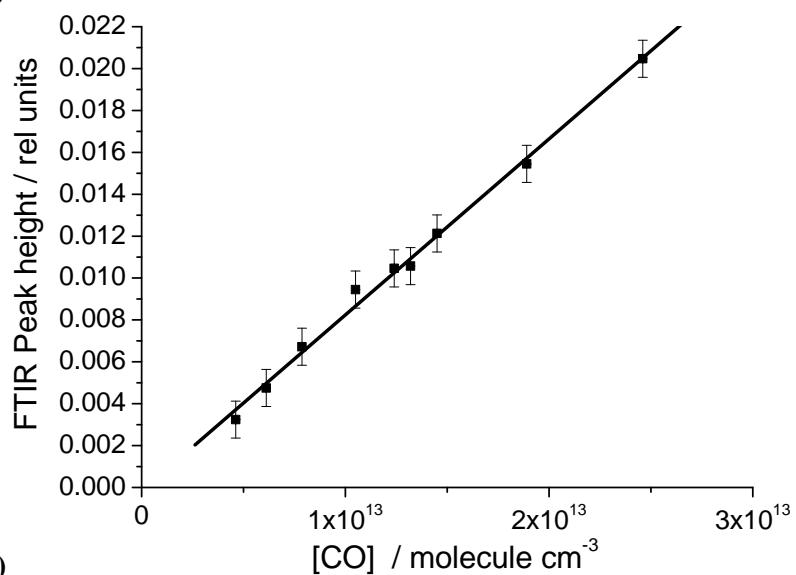

Fig. 9. Correlation plots for intercomparisons staged between the FTIR and: (a) the commerical ozone analyser: gradient = $(8.65 \pm 0.06) \times 10^{-14}$, and intercept $=(3.1 \pm 7.8) \times 10^{-3} ;$ (b) the commercial CO analyser: gradient $=(8.41 \pm 0.49) \times 10^{-16}$, and intercept $=(-1.7 \pm 6.9) \times 10^{-4}$. Errors quoted are standard errors obtained in the regression analysis.

(http://www.spectralcalc.com). In the simulated spectra, the $\mathrm{O}_{3}$ absorption features between $1100-900 \mathrm{~cm}^{-1}$, and the $\mathrm{CO}$ features between $2250-2030 \mathrm{~cm}^{-1}$, were integrated with respect to the baseline, and compared to the same integral values obtained from the experimental spectra. All of the integral values from the experimental spectra agreed with the integral values from the experimental spectra within 5\% (i.e., within the experimental error limits), reaffirming the accuracy of those measured values shown in Fig. 9.

\subsection{Initial GC relative rate experiments}

In order to verify that kinetic data obtained from HIRAC agree with previous literature recommendations (Atkinson and Aschmann, 1985; Lewis et al., 1980) relative rate techniques were used to measure the kinetics of chlorine atom reactions with propane and isobutane under a variety of 


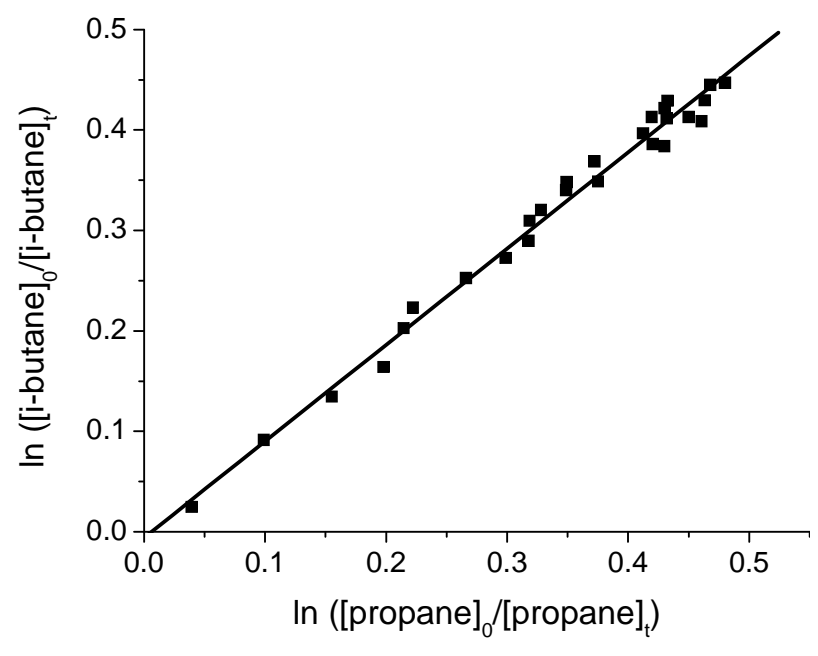

Fig. 10. Typical plot of $\ln \left([\text { isobutane }]_{0} /[\text { isobutane }]_{t}\right)$ versus $\ln \left([\text { propane }]_{0} /[\text { propane }]_{t}\right.$ ) obtained with the $\mathrm{GC}$ following $\mathrm{Cl}_{2}$ irradiation $\left(R^{2}=0.993\right)$.

conditions. The measurements were carried out at room temperature $(298 \pm 2 \mathrm{~K})$ and $1000 \mathrm{mbar}$ in $\mathrm{N}_{2}$ (Dominick Hunter $\mathrm{N}_{2}$ generator, MAX116, $>99.995 \%$ purity). The loss of propane and isobutane was followed using the GCFID with a gas sample valve. The compounds were separated using a $50 \mathrm{~m}, 0.53 \mathrm{~mm}$ i.d. column coated with $100 \%$ dimethylpolysiloxane (J\&W, DB-1) and operated at $50^{\circ} \mathrm{C}$. The organic compounds were of stated purity levels (>99\%), and GC analyses showed no observable impurities. GC samples from HIRAC were obtained using moveable probes, and indicated that concentration gradients across the chamber were insignificant. The reagent concentrations were typically: $10 \mathrm{ppm}$ propane, $10 \mathrm{ppm}$ isobutane, and $20 \mathrm{ppm}$ $\mathrm{Cl}_{2}$. These were introduced into the dark chamber, and $\mathrm{Cl}$ was then generated via the photolysis of $\mathrm{Cl}_{2}$, using four of HIRAC's lamps.

In the relative rate method, the rate of reaction between the compound of interest and a reactive species (e.g., isobutane $+\mathrm{Cl}$ ), is measured with respect to the rate of reaction for some reference compound and the reactive species (e.g., propane $+\mathrm{Cl}$ ). The relative rate $\left(k / k_{\text {ref }}\right.$, e.g., $\left.k_{\mathrm{Cl}+\text { isobutane }} / k_{\mathrm{Cl}+\text { propane }}\right)$ is then obtained from the slope of the plot of $\ln \left([\text { isobutane }]_{0} /[\text { isobutane }]_{t}\right)$ versus $\ln \left([\text { propane }]_{0} /[\text { propane }]_{t}\right)$. A series of kinetic measurements were carried out following $\mathrm{Cl}_{2}$ irradiation, and indicated that: (1) results obtained using dichloromethane as an internal standard were in good agreement with those obtained using chloroform; (2) experiments carried out by introducing the reagents into HIRAC the previous night, and then carrying out the irradiations the following morning, gave results in good agreement with those where the irradiations were performed immediately following reagent mixing. We are not able to directly measure how much $\mathrm{Cl}_{2}$ was lost to the walls overnight, but the results suggest that any uptake has a negligible effect on the kinetic measurements; (3) measurements undertaken with smaller initial concentrations of i-butane and propane $(5 \mathrm{ppm})$ gave results in good agreement with experiments using higher concentrations; (4) results using $\mathrm{Cl}_{2}$ as the $\mathrm{Cl}$ precursor agreed well with those using $\mathrm{COCl}_{2}$. A typical set of results is shown in Fig. 10. For all experiments conducted over the range of conditions mentioned above, the ratio between the rate coefficients $\left(k_{\mathrm{Cl}+\text { isobutane }} / k_{\mathrm{Cl}+\text { propane }}\right)$ is $0.99 \pm 0.02$. The errors obtained for these measurements are the $95 \%$ confidence limits weighted to account for errors in the concentrations of both the isobutane and propane (Brauers and Finlayson-Pitts, 1997; Vetterling, 1988). This value is in good agreement with previous measurements of this ratio: $1.02 \pm 0.04$ (Atkinson and Aschmann, 1985); $0.93 \pm 0.20$ (Lewis et al., 1980); and 1.02 \pm 0.01 (Choi et al., 2006).

\subsection{Pressure dependent relative rate experiments}

To demonstrate HIRAC's capability for performing pressure variable kinetics measurements and in order to stage an intercomparison between the FTIR and GC, relative rate measurements were carried out to investigate the kinetics of $\mathrm{Cl}+$ ethene with respect to $\mathrm{Cl}+$ chloroethane and $\mathrm{Cl}+$ isobutane at room temperature $(298 \pm 2 \mathrm{~K})$. These measurements were performed over a range of pressures, from 15-1000 mbar, using nitrogen as the bath gas (BOC, Oyxgen Free) in order to avoid potential recycling of ethene (Wallington et al., 1990b). GC measurements of the loss of the organic compounds were carried out using the moveable gas sampling system, and compounds were separated using a $1.8 \mathrm{~mm}$ i.d. column coated with a $50 \mathrm{~m}, 0.53 \mathrm{~mm}$ i.d. column operated at $305 \mathrm{~K}$ coated with $100 \%$ dimethylpolysiloxane (J\&W, DB1). The duty cycle varied from $10-15 \mathrm{~h}^{-1}$, depending on the pressure.

Spectroscopic measurements of the loss of the organic species were undertaken by measuring the characteristic absorptions of ethene, isobutane, and chloroethane in the wavelength regions 925-975, 800-850, and $1285-1290 \mathrm{~cm}^{-1}$, respectively. Calibration curves for both the GC and FTIR were obtained for each organic compound over a series of concentrations and, where appropriate, using known mixtures of compounds. The typical initial concentration of each gas (ethene, chloroethane or isobutane, and $\mathrm{Cl}_{2}$ ) was $3 \mathrm{ppm}$. These were introduced into the dark chamber, and $\mathrm{Cl}$ was then generated via the photolysis of $\mathrm{Cl}_{2}$, typically using two of HIRAC's blacklamps. The organic compounds were of stated purity levels (>99\%), and the GC and FTIR analyses obtained for calibration purposes showed no observable impurities.

The relative rate analysis assumes that the reactant and reference organic species are removed solely by reaction with Cl. In order to verify this, the concentrations of the compounds were monitored during each experimental run for 


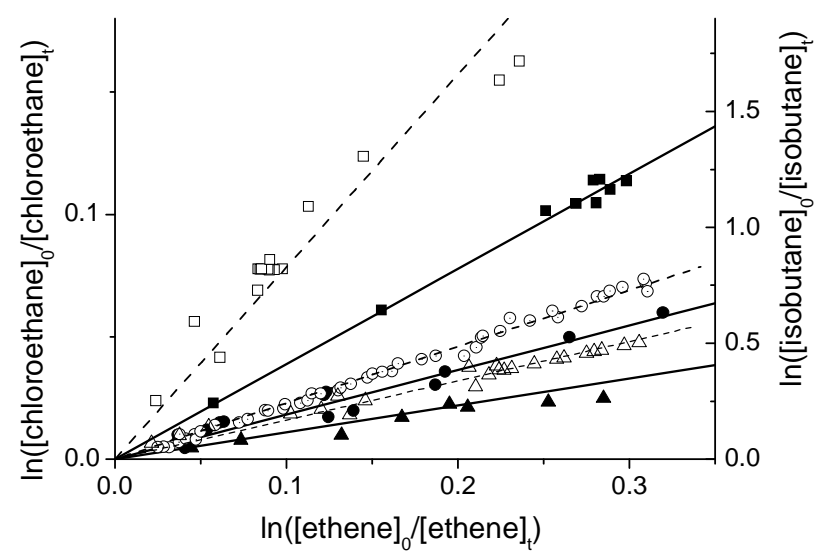

Fig. 11. Plots of $\ln \left([\text { reference }]_{0} /[\text { reference }]_{t}\right)$ versus $\ln \left([\text { ethene }]_{0} /[\text { ethene }]_{t}\right.$ ) obtained with the FTIR following $\mathrm{Cl}_{2}$ irradiation. Dashed lines with open symbols, and solid lines with filled symbols indicate measurements using chloroethane, and isobutane as the reference, respectivley. Triangles, circles, and squares correspond to measurements at 1000, 400, and $100 \mathrm{mbar}$, respectively.

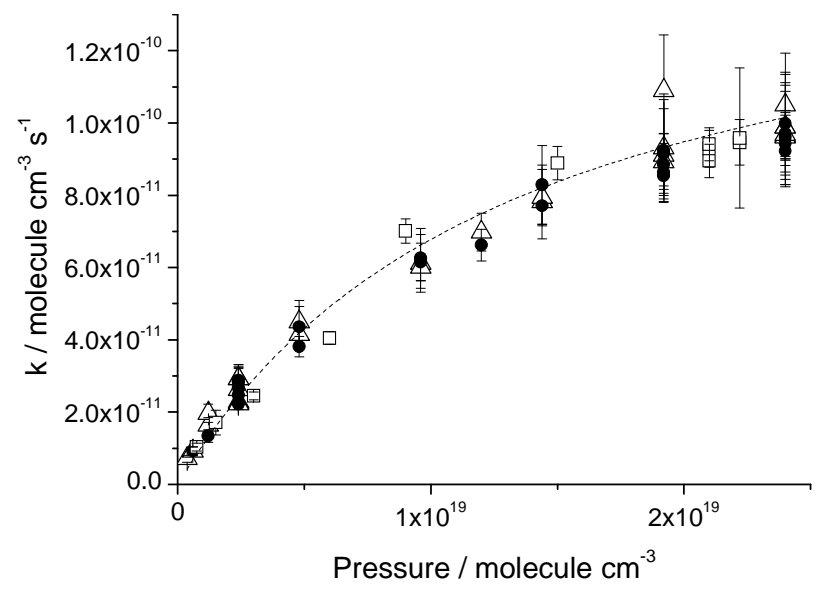

Fig. 12. Fall-off curve showing the rate of loss of $\mathrm{Cl}+$ ethene as a function of total pressure $\mathrm{N}_{2} . \triangle$ and $\square$ represent the data obtained in this work with the FTIR and GC, respectively, and - - the corresponding Troe fit to these data. • represents the data of Kaiser and Wallington (1996).

a period of $\sim 15-30 \mathrm{~min}$, after addition of the reagents to HIRAC, and before the photolysis lights were switched on. Additionally, FTIR and GC measurement of the calibration curves, wherein several measurements were made at each organic concentration, revealed no significant decay of the organics. Typical relative rate plots for each reference compound at a range of pressures, obtained with the FTIR, are shown in Fig. 11. These plots are linear with the intercepts at the origin, within the error limits, suggesting that the present work is free from complications due to secondary chemistry. Table 1 gives the ratio between the rate coefficients
Table 1. a 9 ppm reference ${ }^{b} 9 \mathrm{ppm}$ ethene ${ }^{\mathrm{c}} 10 \mathrm{ppm}(\mathrm{COCl})_{2}$ used as $\mathrm{Cl}$ precursor instead of $3 \mathrm{ppm} \mathrm{Cl}_{2}$.

\begin{tabular}{cccc}
\hline $\begin{array}{c}\text { Pressure/ } \\
\text { mbar }\end{array}$ & Reference & $\begin{array}{c}\text { GC determined } \\
k_{r} / k\end{array}$ & $\begin{array}{c}\text { FTIR determined } \\
k_{r} / k\end{array}$ \\
\hline 15 & Chloroethane & N/A & $1.62 \pm 0.07$ \\
25 & Chloroethane & $1.26 \pm 0.05$ & $1.25 \pm 0.03$ \\
50 & Chloroethane & $0.88 \pm 0.02$ & $0.70 \pm 0.01$ \\
100 & Chloroethane $_{100}$ & $0.39 \pm 0.05$ & $0.39 \pm 0.01$ \\
100 & Isobutane $_{100}$ & $6.06 \pm 0.61$ & $6.67 \pm 0.39$ \\
100 & Isobutane $^{\mathrm{a}}$ & $6.49 \pm 0.23$ & $6.57 \pm 0.26$ \\
100 & Isobutane $^{\mathrm{b}}$ & $6.12 \pm 0.36$ & $6.77 \pm 0.19$ \\
100 & Chloroethane $^{\mathrm{a}}$ & $0.41 \pm 0.03$ & $0.39 \pm 0.01$ \\
200 & Chloroethane $^{\mathrm{b}}$ & $0.42 \pm 0.03$ & $0.44 \pm 0.01$ \\
200 & Chloroethane & $0.26 \pm 0.03$ & $0.26 \pm 0.01$ \\
400 & Isobutane $^{\text {Chloroethane }}$ & $4.09 \pm 0.47$ & $3.64 \pm 0.09$ \\
400 & Isobutane $_{500}$ & $2.45 \pm 0.01$ & $0.19 \pm 0.01$ \\
600 & Isobutane $^{\text {Chloroethane }}$ & $2.41 \pm 0.17$ & $2.51 \pm 0.03$ \\
600 & Isobutane $_{800}$ & $1.96 \pm 0.08$ & $2.16 \pm 0.09$ \\
800 & Chloroethane $^{\text {Isobutane }}$ & $0.13 \pm 0.02$ & $0.15 \pm 0.01$ \\
800 & Chloroethane $^{\mathrm{c}}$ & $0.12 \pm 0.04 \pm 0.07$ & $1.66 \pm 0.15$ \\
800 & Isobutane $^{\mathrm{c}}$ & $1.75 \pm 0.03$ & $0.11 \pm 0.01$ \\
1000 & Chloroethane $_{1000}$ & $0.12 \pm 0.01$ & $0.12 \pm 0.01$ \\
1000 & Isobutane $^{\mathrm{I}}$ & $1.58 \pm 0.12$ & $1.57 \pm 0.05$ \\
1000 & Isobutane $^{\mathrm{a}}$ & $1.61 \pm 0.08$ & $1.57 \pm 0.02$ \\
1000 & Isobutane $^{\mathrm{b}}$ & $1.57 \pm 0.06$ & $1.56 \pm 0.05$ \\
1000 & Chloroethane $^{\mathrm{a}}$ & $0.12 \pm 0.03$ & $0.11 \pm 0.01$ \\
Chloroethane $^{\mathrm{b}}$ & $0.11 \pm 0.03$ & $0.12 \pm 0.01$ \\
\hline & & &
\end{tabular}

obtained for each experimental condition, but does not feature results for measurements carried out under identical conditions. However, we note that several such measurements were performed, and the reproducibility is very good, typically within $4 \%$ for the GC measurements and $7 \%$ for the FTIR measurements. Errors for each point on the regression plot were determined from the standard deviation of a series of measurements of a particular compound maintained at the same concentration. The errors in Table 1 are those obtained from the regression analysis, and reflect the fact that the error in measurement of the compound of interest and the reference compound are similar, as discussed in the previous section.

Using the data in Table 1, and taking the pressure independent rate coefficients for $\mathrm{Cl}$ + chloroethane and $\mathrm{Cl}+$ isobutane to be $(1.15 \pm 0.15) \times 10^{-11} \mathrm{~cm}^{3}$ molecule $\mathrm{e}^{-1} \mathrm{~s}^{-1} \quad$ (Wallington et al., 1990a) and $(1.51 \pm 0.09) \times 10^{-10} \mathrm{~cm}^{3}$ molecule ${ }^{-1} \mathrm{~s}^{-1}$ (Wallington et al., 1988), the ratios of the rate coefficients may be converted to absolute rate coefficients, and fitted to a Troe expression (Troe, 1974) weighted by the experimental uncertainties as shown in Fig. 12. Using a broadening factor of 0.6 (Wallington et al., 1990b; Kaiser and Wallington, 
Table 2. Comparison of the high pressure and low pressure limiting rate coefficients obtained in this work (15-1000 mbar) with those obtained by Kaiser and Wallington (1996) (75-2255 mbar). All errors cited are standard errors.

\begin{tabular}{|c|c|c|c|}
\hline & FTIR (this work) & GC (this work) & Kaiser and Wallington (1996) \\
\hline$k_{0} / \mathrm{cm}^{6}$ molecule ${ }^{-2} \mathrm{~s}^{-1}$ & $(1.25 \pm 0.79) \times 10^{-29}$ & $(1.22 \pm 0.74) \times 10^{-29}$ & $(1.42 \pm 0.05) \times 10^{-29}$ \\
\hline$k_{\infty} / \mathrm{cm}^{3}$ molecule ${ }^{-1} \mathrm{~s}^{-1}$ & $(1.45 \pm 0.15) \times 10^{-10}$ & $(1.42 \pm 0.14) \times 10^{-10}$ & $(3.2 \pm 0.15) \times 10^{-10}$ \\
\hline
\end{tabular}

1996), $\quad k_{0}=(1.22 \pm 0.74) \times 10^{-29} \mathrm{~cm}^{6}$ molecule ${ }^{-2} \mathrm{~s}^{-1} \quad$ and $k_{\infty}=(1.42 \pm 0.14) \times 10^{-10} \mathrm{~cm}^{3}$ molecule ${ }^{-1} \mathrm{~s}^{-1}$ for the data obtained with the GC. For the data obtained with the FTIR, $k_{0}=(1.25 \pm 0.79) \times 10^{-29} \mathrm{~cm}^{6}$ molecule ${ }^{-2} \mathrm{~s}^{-1}$ and $k_{\infty}=(1.45 \pm 0.15) \times 10^{-10} \mathrm{~cm}^{3}$ molecule ${ }^{-1} \mathrm{~s}^{-1}, \quad$ in good agreement with the values obtained using the GC data. The low pressure termolecular rate coefficients, $k_{0}$, determined in this work agree well with those determined by Wallington et al. (1990b) and Kaiser and Wallington (1996), but the high pressure bimolecular rate coefficients are roughly a factor of two slower than those determined by the same authors, as shown in Table 2. These other studies investigated pressures between 0.15 and $2255 \mathrm{mbar}$, and even at these high pressures, the data do not appear to have reached the high pressure limit, whereas the data obtained in the present study appear to be approaching the high pressure limit at 1000 mbar. At atmospheric pressure and below, the data obtained in all studies are in good agreement.

We are aware of controversy regarding the absolute value for the rate coefficient for the $\mathrm{Cl}+$ chloroethane reference reaction. Unfortunately, only a limited number of reference compounds are available for the $\mathrm{Cl}+$ ethene reaction at low pressure. We have used a value determined in a relative rate study against ethane (Wallington et al., 1990a). Direct measurements (Bryukov et al., 2003) report a value of approximately $8 \times 10^{-12} \mathrm{~cm}^{3}$ molecule ${ }^{-1} \mathrm{~s}^{-1}$, some $30 \%$ lower. Our absolute values for $\mathrm{Cl}+$ ethene from both reference compounds are consistent if the higher value for $\mathrm{Cl}$ + chloroethane is used, although the errors are of the order of $\pm 20 \%$, which are comparable to the systematic errors in the $\mathrm{Cl}+$ chloroethane rate coefficient. This issue will be addressed in further studies on $\mathrm{Cl}$ atom kinetics.

\subsection{Ozonolysis experiments}

The capability of HIRAC to quantitatively measure freeradicals has been investigated by examining the reaction of $\mathrm{O}_{3}+\mathrm{t}$-2-butene, which is known to produce $\mathrm{OH}$ and acetaldehyde (Rickard et al., 1999; Calvert et al., 2000). The experiments were conducted in synthetic air at room temperature and a total pressure of 1000 mbar. The absorption bands of acetaldehyde in the region $1762 \mathrm{~cm}^{-1}$ were measured using the FTIR, $\mathrm{O}_{3}$ was measured with the commercial analyser, and $\mathrm{OH}$ was monitored with the FAGE instrument described above. $\mathrm{O}_{3}$ was generated by photolysing $\mathrm{O}_{2}$ flowed over a
$\mathrm{Hg}$ pen-ray lamp until the chamber $\left[\mathrm{O}_{3}\right]$ reached $\sim 1 \mathrm{ppm}$, during which time HIRAC samples were replenished by $\mathrm{O}_{2}$. Then, the FAGE sampling pumps were turned on, HIRAC gas samples were replenished by $\mathrm{N}_{2}$, and $1 \mathrm{ppm} \mathrm{t}$-2-butene was added to HIRAC. Throughout the experiment, all four of HIRAC's fans were run at $50 \%$ of their maximum speed. Additional experimental runs using either laboratory air or pure $\mathrm{N}_{2}$ for the bath gas were also carried out. The rate of $\mathrm{O}_{3}$ decay in the dark chamber was measured before and after the experimental runs, and found to be proportional to $\left[\mathrm{O}_{3}\right]$, with a unimolecular loss rate determined to be $\sim 3.2 \times 10^{-5} \mathrm{~s}^{-1}$.

Data obtained from these reactions for the time dependent $\mathrm{OH}$ profile, as well as the growth and decay of acetaldehyde and $\mathrm{O}_{3}$, respectively, in nitrogen bath gas are shown in Figs. 13a and b. Also shown in these figures is the comparison between the measured $[\mathrm{OH}]$ and model predictions obtained using a chemical model based on the MCM (Saunders et al., 2003; Jenkin et al., 1997, 2003) and integrated using FACSIMILE (MCPA software, Oxon, UK). The MCM subset extracted for these simulations included 54 intermediates and 124 reactions. MCM v3.1 specifies that $57 \%$ of the Criegee biradical intermediate formed from the $\mathrm{O}_{3}+\mathrm{t}$-2-butene reaction yields $\mathrm{OH}$. The peak modelled $[\mathrm{OH}]=4.50 \times 10^{7}$ molecules $\mathrm{cm}^{-3}$, in agreement with the experimental value of $(4.60 \pm 1.06) \times 10^{7}$ ( $1 \mathrm{~s}$ signal averaging $)$. The reduction of $[\mathrm{OH}]$ with respect to its peak value, observed in Fig. 13a, is due $\mathrm{OH}$ reactions with products of the ozonolysis reactions and t-2-butene, which become significant as the rate of $\mathrm{OH}$ production drops off due to reduced concentrations of $\mathrm{O}_{3}$ and $\mathrm{t}$-2-butene. Within error, the modelled and measured $[\mathrm{OH}]$ and $\left[\mathrm{O}_{3}\right]$ are in good agreement. Similar to other studies of $\mathrm{O}_{3}+\mathrm{t}-2$-butene oxidation, the residual plot in Fig. 13b indicates that the measured acetaldehyde is slightly higher than the modelled acetaldehyde, likely due to the presence of carbonyl compounds formed by subsequent reactions of the Criegee biradicals (Calvert et al., 2000).

Because the FAGE instrument calibration was carried out in synthetic air, the effect of $\mathrm{O}_{2}$ quenching of the $\mathrm{OH}$ fluorescence LIF signal was investigated for determination of $[\mathrm{OH}]$ in $\mathrm{N}_{2}$. The $\mathrm{OH}$ LIF signal recorded in pure $\mathrm{N}_{2}$ was larger than the signal for the identical experiment carried out in synthetic air. The difference in signal has been attributed to the fact that $\mathrm{O}_{2}$ has a larger rate coefficient for collisional quenching of excited $\mathrm{OH}$ than $\mathrm{N}_{2}$. These have been 
measured at $294 \mathrm{~K}$ to be $1.39 \times 10^{-10} \mathrm{~cm}^{3}$ molecule ${ }^{-1} \mathrm{~s}^{-1}$ and $3.40 \times 10^{-11} \mathrm{~cm}^{3}$ molecule ${ }^{-1} \mathrm{~s}^{-1}$, respectively (Bailey et al., 1997). The change in sensitivity for $\mathrm{OH}$ detection observed between $\mathrm{O}_{3}+\mathrm{t}$-2-butene experiments carried out in pure $\mathrm{N}_{2}$ of and those observed in synthetic air (0.67) is in good agreement with calculations of the fluoresence quantum yields of $\mathrm{OH}$ in $\mathrm{N}_{2}$ and synthetic air using the coefficients of collisional quenching cited above and the detection timing gates $(0.70)$. In these experiments, the water vapour was less than $0.03 \%$ (the threshold of the calibration, discussed above). However, the good agreement between model and the measurements suggests that the $\mathrm{OH}$ fluorescence signal is not sensitive to the decreased $\left[\mathrm{H}_{2} \mathrm{O}\right]$ for the geometry of the HIRAC FAGE expansion. Further experiments are planned to examine the dependence of the $\mathrm{OH}$ fluorescence signal on $\left[\mathrm{H}_{2} \mathrm{O}\right]$.

This work demonstrates HIRAC's potential to simulate a range of atmospheric compositions, pressures, and temperatures. It thereby offers a test-bed for calibration and investigation of the FAGE instrument response, so long as a reliable means for generating a known $[\mathrm{OH}]$ is available. Furthermore, the measurements described above indicate HIRAC's potential to measure the time dependent profiles of a range of species, including radical concentrations.

\section{Conclusion}

We have demonstrated that HIRAC, a highly instrumented photochemical reaction chamber, has the potential to perform detailed pressure dependent studies on gas phase chemical systems over a range of atmospheric conditions. It features a suite of analytical instrumentation, including: a multipass FTIR system coupled to a Chernin cell; a commerical GC FID and a home built formaldehyde GC, both of which are coupled to an automated sampling system; commercial NO and $\mathrm{NO}_{2}, \mathrm{CO}, \mathrm{O}_{3}$, and $\mathrm{H}_{2} \mathrm{O}$ analysers; and a LIF FAGE instrument for performing $\mathrm{OH}$ and $\mathrm{HO}_{2}$ radical measurements. Its capabilities and its coupling to the FAGE instrument for in situ radical detection establish it as internationally unique for a chamber of its size. Intercomparisons of the instruments coupled to HIRAC indicate good agreement, and it has been used to investigate pressure dependent kinetics, giving good agreement with previously reported literature results. Besides kinetics applications, HIRAC has been used to examine the reaction of $\mathrm{O}_{3}$ and $\mathrm{t}$-2-butene and the corresponding $\mathrm{OH}$ yields, and the results obtained are in good agreement with the mechanism featured in the current version of the Master Chemical Mechanism (v3.1).

HIRAC may be used for a range of applications in atmospheric chemistry, including: (1) field instrument intercomparison, calibration, development, and investigations of instrument response at a range of atmospheric conditions; (2) kinetics investigations over a range of atmospherically relevant conditions, with the potential for providing highly accu-

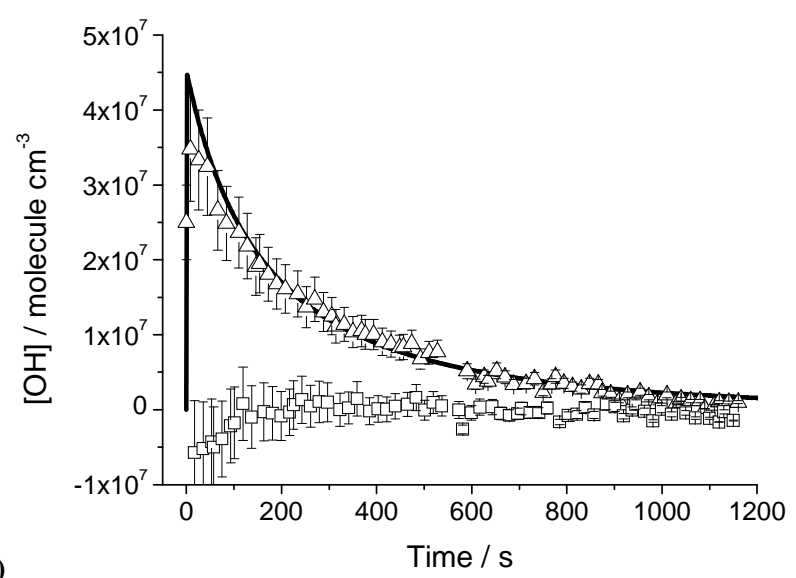

(a)

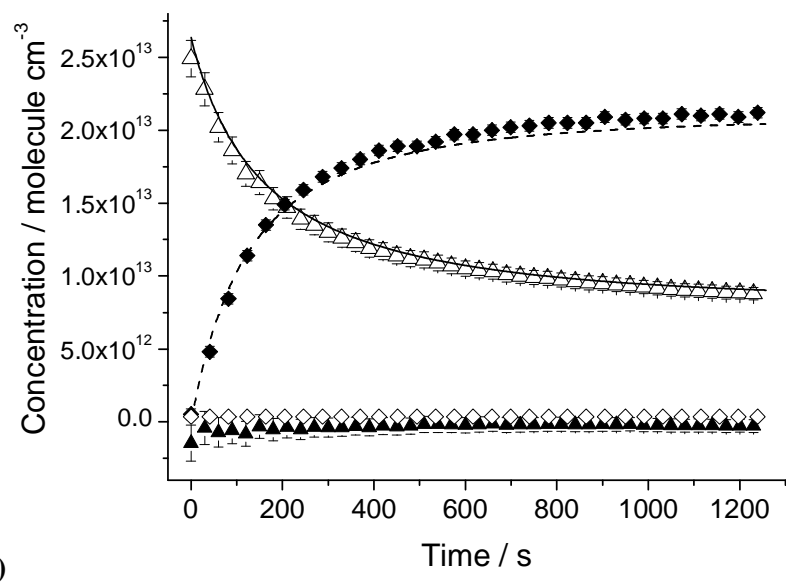

Fig. 13. (a) Time dependent $[\mathrm{OH}]$ in HIRAC for the reaction of $\mathrm{O}_{3}+\mathrm{t}$-2-butene, obtained with the FAGE LIF instrument ( $5 \mathrm{~s}$ signal averaging; for the sake of a clearer plot, every third point is shown). The solid line represents model results generated with MCM v3.1. Open squares $\square$ show the residual plot and associated errors. (b) Time dependent $\left[\mathrm{O}_{3}\right](\triangle)$ and $\left[\mathrm{CH}_{3} \mathrm{CHO}\right](\checkmark)$ profiles in HIRAC for the reaction of $\mathrm{O}_{3}+\mathrm{t}$-2-butene, obtained with the $\mathrm{O}_{3}$ analyser and FTIR, respectively. The solid line and dotted lines represent the corresponding MCM v3.1 predictions, and $\boldsymbol{\Delta}$ and $\diamond$ the corresponding residual plots.

rate kinetic data; and (3) the potential to facilitate mechanism development and validation, which is significantly enhanced by its ability to both perform in situ radical measurements and measure several species simultaneously. Future experiments will investigate whether the radical measurements in HIRAC have any dependency upon position of the sampling pinhole with respect to the radiation field profile, and total pressure. Additionally, we plan to couple a cavity ring down spectroscopy (CRDS) apparatus to HIRAC for detection of key oxidation products such as glyoxal, as well as to add the facility for carrying out temperature variable experiments.

Acknowledgements. Construction of HIRAC was funded by NERC grant NEC513493/1. D. R. Glowacki's Overseas Research 
Studentship was provided by Universities UK and a University of Leeds Tetley and Lupton scholarship, with additional funding from EU EUROCHAMP program (RII3-CT-2004-505968). K. Hemavibool's studentship was provided by the Royal Thai Government. For tours, helpful discussions, and recommendations regarding reaction chamber design, we would like to thank the staff and faculty that manage the reaction chambers at the University of Wuppertal and the SAPHIR chamber at Forschungszentrum Jülich. We also thank the mechanical and electronic workshops in The School of Chemistry at the University of Leeds, the staff at Bruker Optics, P. Monks' group at the University of Leicester for use of their filter radiometer, and NTE Vacuum Systems. Individuals we want to thank include P. Turner, J. Dixon, E. Kennedy, N. Oldham, A. Hofzumahaus, F. Holland, R. Phillips, M. T. Baeza-Romero, J. McQuaid, and I. Barnes.

Edited by: J. Thornton

\section{References}

Akimoto, H., Hoshino, M., Inoue, G., Sakamaki, F., Washida, N., and Okuda, M.: Design and characterization of the evacuable and bakable photochemical smog chamber, Environ. Sci. Technol., 13, 471-475, 1979.

Atkinson, R. and Aschmann, S. M.: Kinetics of the gas phase reaction of chlorine atoms with a series of organics at $296 \pm 2 \mathrm{~K}$ and atmospheric pressure, Int. J. Chem. Kin., 17, 33-41, 1985.

Baeza-Romero, M. T., Glowacki, D. R., Blitz, M. A., Heard, D. E., Pilling, M. J., Rickard, A. R., and Seakins, P. W.: A combined experimental and theoretical study of the reaction between methylglyoxal and OH/OD radical: OH regeneration, Phys. Chem. Chem. Phys. FIELD: PCCP, 9, 4114-4128, 2007.

Bailey, A. E., Heard, D. E., Paul, P. H., and Pilling, M. J.: Collisional quenching of $\mathrm{OH}\left(\mathrm{A} 2 \mathrm{~S}+, n^{\prime}=0\right) \mathrm{N}_{2}, \mathrm{O}_{2}$ and $\mathrm{CO}_{2}$ between 204 and $294 \mathrm{~K}$ : Implications for atmospheric measurements of $\mathrm{OH}$ by laser-induced fluorescence, J. Chem. Soc. Faraday T., 93, 2915-2920, 1997.

Baltensperger, U., Kalberer, M., Dommen, J., Paulsen, D., Alfarra, M. R., Coe, H., Fisseha, R., Gascho, A., Gysel, M., Nyeki, S., Sax, M., Steinbacher, M., Prevot, A. S. H., Sjogren, S., Weingartner, E., and Zenobi, R.: Secondary organic aerosols from anthropogenic and biogenic precursors, Faraday Discuss., 130, 265-278, 2005.

Barnes, I., Becker, K. H., and Mihalopoulos, N.: An FTIR Product Study of the Photooxidation of Dimethyl Disulfide, J. Atmos. Chem., 18, 267-289, 1994.

Becker, K. H.: "EUPHORE, The European Photoreactor." The construction and operation of an outdoor smog chamber in Valencia for studying mechanisms of photochemical processes and their modeling in the polluted air of different European regions. Design and technical development of the European photoreactor and first experimental results, Final Report, DG 12 contract EV5VCT92-0059, European Community, Brussels, 1996.

Bernstein, H. J. and Herzberg, J.: Rotation-Vibration Spectra of Diatomic and Simple Polyatomic Molecules with Long Absorbing Paths, J. Chem. Phys., 16, 30-39, 1948.

Bloss, C., Wagner, V., Bonzanini, A., Jenkin, M. E., Wirtz, K., Martin-Reviejo, M., and Pilling, M. J.: Evaluation of detailed aromatic mechanisms (MCMv3 and MCMv3.1) against environmental chamber data, Atmos. Chem. Phys., 5, 623-639, 2005a.

Bloss, C., Wagner, V., Jenkin, M. E., Volkamer, R., Bloss, W. J., Lee, J. D., Heard, D. E., Wirtz, K., Martin-Reviejo, M., Rea, G., Wenger, J. C., and Pilling, M. J.: Development of a detailed chemical mechanism (MCMv3.1) for the atmospheric oxidation of aromatic hydrocarbons, Atmos. Chem. Phys., 5, 641-664, 2005 b.

Bloss, W. J., Gravestock, T. J., Heard, D. E., Ingham, T., Johnson, G. P., and Lee, J. D.: Application of a compact all solid-state laser system to the in situ detection of atmospheric $\mathrm{OH}, \mathrm{HO}$, $\mathrm{NO}$ and IO by laser-induced fluorescence, J. Environ. Monitor., 5, 21-28, 2003.

Bohn, B., Rohrer, F., Brauers, T., and Wahner, A.: Actinometric measurements of $\mathrm{NO}_{2}$ photolysis frequencies in the atmosphere simulation chamber SAPHIR, Atmos. Chem. Phys., 5, 493-503, 2005 , http://www.atmos-chem-phys.net/5/493/2005/.

Bohn, B. and Zilken, H.: Model-aided radiometric determination of photolysis frequencies in a sunlit atmosphere simulation chamber, Atmos. Chem. Phys., 5, 191-206, 2005, http://www.atmos-chem-phys.net/5/191/2005/.

Brauers, T. and Finlayson-Pitts, B. J.: Analysis of relative rate measurements, Int. J. Chem. Kin., 29, 665-672, 1997.

Bryukov, M. G., Slagle, I. R., and Knyazev, V. D.: Kinetics of Reactions of $\mathrm{Cl}$ Atoms with Ethane, Chloroethane, and 1,1Dichloroethane, J. Phys. Chem. A, 107, 6565-6573, 2003.

Calvert, J. G., Kerr, J. A., Madronich, S., Moortgat, G. K., Wallington, T. J., and Yarwood, G.: The Mechanisms of Atmospheric Oxidation of the Alkenes, 560 pp., 2000.

Cantrell, C. A., Zimmer, A., and Tyndall, G. S.: Absorption cross sections for water vapor from 183 to $193 \mathrm{~nm}$, Geophys. Res. Lett., 24, 2195-2198, 1997.

Carter, W. P. L., Luo, D., Malkina, I., and Pierce, J.: Environmental Chamber Studies of Atmospheric Reactivities of Volatile Organic Compounds. Effects of Varying Chamber and Light Source, Final report to National Renewable Energy Laboratory., Contract XZ-2-12075, Coordinating Research Council, Inc., Project M-9, California Air Resources Board, Contract A032-0692, and South Coast Air Quality Management District, Contract C91323, March 26, available at http://www.cert.ucr. edu/ $\sim$ carter/absts.htm\#explrept, Riverside, 1995.

Carter, W. P. L.: Development of a Next Generation Environmental Chamber Facility For Chemical Mechanism and VOC Reactivity Research, Center for Environmental Research and Technology, College of Engineering, University of California, Riverside, California, 2002.

Carter, W. P. L., Cocker, D. R., Fitz, D. R., Malkina, I. L., Bumiller, K., Sauer, C. G., Pisano, J. T., Bufalino, C., and Song, C.: A new environmental chamber for evaluation of gas-phase chemical mechanisms and secondary aerosol formation, Atmos. Environ., 39, 7768-7788, 2005.

Cassano, A. E., Martin, C., Brandi, R., and Alfano, O.: Photoreactor Analysis and Design: Fundamentals and Applications, Industrial Eng. Chem. Res., 34, 2155-2201, 1995.

Chernin, S. and Barskaya, E.: Optical multipass matrix systems, Appl. Optics, 30, 51-58, 1991.

Chernin, S.: Promising Version of the three-objective multipass matrix system, Opt. Express, 10, 104-107, 2002. 
Choi, N., Pilling, M. J., Seakins, P. W., and Wang, L.: Studies of site selective hydrogen atom abstractions by $\mathrm{Cl}$ atoms from isobutane and propane by laser flash photolysis/IR diode laser spectroscopy, Phys. Chem. Chem. Phys., 8, 2172-2178, 2006.

Cornejo-Rodriguez, A.: Ronchi Test, in: Optical Shop Testing, 3 ed., edited by: Malacara, D., Wiley, 2007.

Creasey, D. J., Halford-Maw, P. A., Heard, D. E., Spence, J. E., and Whitaker, B. J.: Fast photomultiplier tube gating system for photon counting applications, Rev. Sci. Instrum., 69, 4068-4073, 1998.

DeMore, W., Sander, S., Golden, D., Hampson, R., Kurylo, M., Howard, C., Ravishankara, A., Kolb, C., and Molina, M.: Chemical kinetics and photochemical data for use in stratospheric modeling, evaluation number 12, in: JPL Publications, Jet Propulsion Laboratory, California Institute of Technology, Pasadena, 97-94, 1997.

Denman, K. L. and Brasseur, G.: Couplings Between Changes in the Climate System and Biogeochemistry, in: Climate Change 2007: The Physical Science Basis, Intergovernmental Panel on Climate Change, 2007.

Dodge, M. C.: Chemical Oxidant Mechanisms for Air Quality Modeling: A critical review, Atmos. Environ., 34, 2103-2130, 2000.

Doussin, J.-F., Dominique, R., and Patrick, C.: Multiple-pass cell for very-long-path infrared spectroscopy, Appl. Optics, 38, 4145-4150, 1999.

Doussin, J. F., Ritz, D., Durand-Jolibois, R., Monod, A., and Carlier, P.: Design of an environmental chamber for the study of atmospheric chemistry: new developments in the analytical device, Analusis, 25, 236-242, 1997.

Edwards, G. D., Cantrell, C. A., Stephens, S., Hill, B., Goyea, O., Shetter, R. E., Mauldin, R. L., III, Kosciuch, E., Tanner, D. J., and Eisele, F. L.: Chemical Ionization Mass Spectrometer Instrument for the Measurement of Tropospheric HO2 and RO2, Anal. Chem., 75, 5317-5327, 2003.

Faloona, I. C., Tan, D., Lesher, R. L., Hazen, N. L., Frame, C. L., Simpas, J. B., Harder, H., Martinez, M., Di Carlo, P., Ren, X., and Brune, W. H.: A Laser-induced Fluorescence Instrument for Detecting Tropospheric $\mathrm{OH}$ and $\mathrm{HO} 2$ : Characteristics and Calibration, J. Atmos. Chem., 47, 139-167, 2004.

Floquet, C. F. A.: Airborne Measurements of Hydroxyl Radicals by Fluorescene Assay by Gas Expansion, Chemistry, University of Leeds, Leeds, 2006.

Forster, P. and Ramaswamy, V.: Changes in Atmospheric Constituents and in Radiative Forcing, in: Climate Change 2007: The Physical Science Basis, Intergovernmental Panel on Climate Change, 2007.

Gannon, K. L., Glowacki, D. R., Blitz, M. A., Hughes, K. J., Pilling, M. J., and Seakins, P. W.: H Atom Yields from the Reactions of CN Radicals with $\mathrm{C}_{2} \mathrm{H}_{2}, \mathrm{C}_{2} \mathrm{H}_{4}, \mathrm{C}_{3} \mathrm{H}_{6}$, trans-2- $\mathrm{C}_{4} \mathrm{H}_{8}$, and iso$\mathrm{C}_{4} \mathrm{H}_{8}$, J. Phys. Chem. A, 111, 6679-6692, 2007.

Glowacki, D. R., Goddard, A., and Seakins, P. W.: Design and Performance of a Throughput-Matched, Zero-Geometric-Loss, Modified Three Objective Multipass Matrix System for FTIR spectrometry, Appl. Optics, accepted, 2007.

Gordley, L. L., Marshall, B. T., and Chu, D. A.: Linepak: algorithms for modeling spectral transmittance and radiance, J. Quant. Spectr. Radiat. Trans., 52, 563-580, 1994.

Grassi, L. and Guzzi, R.: Theoretical and practical considera- tion of the construction of a zero-geometric-loss multiple-pass cell based on the use of monolithic mutliple-face retroreflectors, Appl. Optics, 40, 6062-6071, 2001.

Hanst, P. L.: Spectroscopic Methods for Air Pollution Measurement, Adv. Environ. Sci.Technol., 2, 91-213, 1971.

Heard, D. E. and Pilling, M. J.: Measurement of $\mathrm{OH}$ and $\mathrm{HO}_{2}$ in the Troposphere, Chem. Rev., 103, 5163-5198, 2003.

Heard, D. E.: Atmospheric field measurements of the hydroxyl radical using laser-induced fluorescence spectroscopy, Ann. Rev. Phys. Chem., 57, 191-216, 2006.

Hopkins, J. R., Still, T., Al-Haider, S., Fisher, I. R., Lewis, A. C., and Seakins, P. W.: A simplified apparatus for ambient formaldehyde detection via GC-pHID, Atmos. Environ., 37, 2557-2565, 2003.

Horn, D. and Pimentel, G. C.: 2.5-km Low Temperature Multiple Reflection Cell, Appl. Optics, 10, 1892-1898, 1971.

Irazoqui, H. A., Cerda, J., and Cassano, A. E.: The Radiation Field for the Point and Line Source Approximations and the ThreeDimensional Source Models: Applications to Photoreactors, The Chemical Engineering Journal, 11, 27-37, 1976.

Jenkin, M. E., Saunders, S. M., and Pilling, M. J.: The tropospheric degredation of volatile organic compounds: a protocol for mechanism development, Atmos. Environ., 31, 81-104, 1997.

Jenkin, M. E., Saunders, S. M., Wagner, V., and Pilling, M. J.: Protocol for the development of the Master Chemical Mechanism, MCM v3 (part B): tropospheric degradation of aromatic volatile organic compounds, Atmos. Chem. Phys., 3, 181-193, 2003, http://www.atmos-chem-phys.net/3/181/2003/.

Kaiser, E. W. and Wallington, T. J.: Kinetics of the Reactions of Chlorine with $\mathrm{C}_{2} \mathrm{H}_{4}\left(\mathrm{k}_{1}\right)$ and $\mathrm{C}_{2} \mathrm{H}_{2}\left(\mathrm{k}_{2}\right)$ : A Determination of $\Delta \mathrm{H}_{f}$, 298 Deg for $\mathrm{C}_{2} \mathrm{H}_{3}$, J. Phys. Chem., 100, 4111-4119, 1996.

Kwok, E. S. C. and Atkinson, R.: Estimation of hydroxyl radical reaction rate constants for gas-phase organic compounds using a structure-reactivity relationship: an update, Atmos. Environ., 29, 1685-1695, 1995.

Lewis, R. S., Sander, S. P., Wagner, S., and Watson, R. T.: Temperature-dependent rate constants for the reaction of groundstate chlorine with simple alkanes, J. Phys. Chem., 84, 20092015, 1980.

McKee, K. W., Blitz, M. A., Cleary, P. A., Glowacki, D. R., Pilling, M. J., Seakins, P. W., and Wang, L.: Experimental and Master Equation Study of the Kinetics of $\mathrm{OH}+\mathrm{C}_{2} \mathrm{H}_{2}$ : Temperature Dependence of the Limiting High Pressure and Pressure Dependent Rate Coefficients, J. Phys. Chem. A., 111, 4043-4055, 2007.

Miller, J. A., Pilling, M. J., and Troe, J.: Unravelling combustion mechanisms through a quantitative understanding of elementary reactions, Proceedings of the Combustion Institute, 30, 43-88, Part 1, 2005.

Nolting, F., Behnke, W., and Zetzsch, C.: A smog chamber for studies of the reactions of terpenes and alkanes with ozone and hydroxyl, J. Atmos. Chem., 6, 47-59, 1988.

Pinelli, D., Bujalski, W., Nienow, A. W., and Magelli, F.: Comparison of experimental techniques for the measurement of mixing time in gas-liquid systems, Chem. Eng. Technol., 24, 919-923, 2001.

Ravishankara, A. R.: Chemistry-climate coupling: The importance of chemistry in climate issues, Faraday Discuss., 130, 9-26, 2005. 
Ren, X., Harder, H., Martinez, M., Faloona, I. C., Tan, D., Lesher, R. L., Di Carlo, P., Simpas, J. B., and Brune, W. H.: Interference Testing for Atmospheric HOx Measurements by Laser-induced Fluorescence, J. Atmos. Chem., 47, 169-190, 2004.

Rickard, A. R., Johnson, D., McGill, C. D., and Marston, G.: OH Yields in the Gas-Phase Reactions of Ozone with Alkenes, J. Phys. Chem. A., 103, 7656-7664, 1999.

Rothman, L. S., Jacquemart, D., Barbe, A., Benner, D. C., Birk, M., Brown, L. R., Carleer, M. R., Chackerian, C., Chance, K., Coudert, L. H., Dana, V., Devi, V. M., Flaud, J. M., Gamache, R. R., Goldman, A., Hartmann, J. M., Jucks, K. W., Maki, A. G., Mandin, J. Y., Massie, S. T., Orphal, J., Perrin, A., Rinsland, C. P., Smith, M. A. H., Tennyson, J., Tolchenov, R. N., Toth, R. A., Vander Auwera, J., Varanasi, P., and Wagner, G.: The HITRAN 2004 molecular spectroscopic database, J. Quant. Spectr. Radiat. Trans., 96, 139-204, 2005.

Saunders, S., Jenkin, M., Derwent, R., and Pilling, M.: Protocol for the development of the Master Chemical Mechanism, MCM v3 (Part A): tropospheric degredation of non-aromatic volatile organic compounds, Atmos. Chem. Phys., 3, 161-180, 2003, http://www.atmos-chem-phys.net/3/161/2003/.

Seinfeld, J. H.: Air pollution: A half century of progress, AIChE Journal, 50, 1096-1108, 2004.

Shetter, R. E., Davidson, J. A., Cantrell, C. A., and Calvert, J. G.: Temperature variable long path cell for absorption measurements, Rev. Sci. Instrum., 58, 1427-1428, 1987.

Sommariva, R., Pilling, M. J., Bloss, W. J., Heard, D. E., Lee, J. D., Fleming, Z. L., Monks, P. S., Plane, J. M. C., Saiz-Lopez, A., Ball, S. M., Bitter, M., Jones, R. L., Brough, N., Penkett, S. A., Hopkins, J. R., Lewis, A. C., and Read, K. A.: Nighttime radical chemistry during the NAMBLEX campaign, Atmos. Chem. Phys., 7, 587-598, 2007,

http://www.atmos-chem-phys.net/7/587/2007/.

Still, T. J., Al-Haider, S., Seakins, P. W., Sommariva, R., Stanton, J. C., Mills, G., and Penkett, S. A.: Ambient formaldehyde measurements made at a remote marine boundary layer site during the NAMBLEX campaign - a comparison of data from chromatographic and modified Hantzsch techniques, Atmos. Chem. Phys., 6, 2711-2726, 2006,

http://www.atmos-chem-phys.net/6/2711/2006/.

Stone, D. A.: A controlled-environment chamber for atmospheric chemistry studies using FT-IR spectroscopy, Appl. Spectrosc., 44, 945-950, 1990.

Thüner, L. P., Bardini, P., Rea, G. J., and Wenger, J. C.: Kinetics of the Gas-Phase Reactions of $\mathrm{OH}$ and $\mathrm{NO}_{3}$ Radicals with Dimethylphenols, J. Phys. Chem. A, 108, 11 019-11 025, 2004.

Tobin, D. C., Strow, L., Lafferty, J., and Olson, W. B.: Experimental Investigation of the self and $\mathrm{N}_{2}$ broadened continuum within the v2 band of water vapor, Appl. Optics, 35, 4724-4734, 1996.
Troe, J.: Fall-off curves of unimolecular reactions, Berichte der Bunsen-Gesellschaft, 78, 478-488, 1974.

Tyndall, G. S., Orlando, J. J., Wallington, T. J., and Hurley, M. D.: Pressure Dependence of the Rate Coefficients and Product Yields for the Reaction of $\mathrm{CH}_{3} \mathrm{CO}$ Radicals with $\mathrm{O}_{2}$, Int. J. Chem. Kin., 29, 655-663, 1997.

Vetterling, W. T.: Straight Line Data with Errors in Both Coordinates, in: Numerical Recipes in C, Cambridge University Press, Cambridge, 666-670, 1988.

Voigt, S., Orphal, J., and Burrows, J. P.: The temperature and pressure dependence of the absorption cross-sections of NO2 in the $250-800 \mathrm{~nm}$ region measured by Fourier-transform spectroscopy, J. Photoch. and Photobio. A, 149, 1-7, 2002.

Wahner, A.: SAPHIR: Simulation of Atmospheric Photochemistry in a Large Reaction Chamber: A novel instrument, Abstr. Pap. Am. Chem. Soc., 224, 082-PHYS, 2002.

Wallington, T. J., Skewes, L. M., Siegl, W. O., Wu, C. H., and Japar, S. M.: Gas phase reaction of chlorine atoms with a series of oxygenated organic species at $295 \mathrm{~K}$, Int. J. Chem. Kin., 20, 867875, 1988.

Wallington, T. J. and Japar, S. M.: Fourier transform infrared kinetic studies of the reaction of nitrous acid with nitric acid, nitrogen trioxide $\left(\mathrm{NO}_{3}\right)$ and dinitrogen pentoxide $\left(\mathrm{N}_{2} \mathrm{O}_{5}\right)$ at $295 \mathrm{~K}, \mathrm{~J}$. Atmos. Chem., 9, 399-409, 1989.

Wallington, T. J., Andino, J. M., Ball, J. C., and Japar, S. M.: Fourier transform infrared studies of the reaction of chlorine atoms with peroryacetyl nitrate (PAN), peroxypropionyl nitrate, methyl hydroperoxide, formic acid, acetone, and 2-butanone at 295 \pm 2 K, J. Atmos. Chem., 10, 301-313, 1990a.

Wallington, T. J., Andino, J. M., Lorkovic, I. M., Kaiser, E. W., and Marston, G.: Pressure dependence of the reaction of chlorine atoms with ethene and acetylene in air at $295 \mathrm{~K}$, J. Phys. Chem., 94, 3644-3648, 1990b.

Wallington, T. J. and Nielsen, O. J.: Measurement of rate constants for radical reactions in the gas phase, in: General Aspects of Free Radical Chemistry, edited by: Alfassi, Z., John Wiley, 19-50, 1999.

White, J.: Long optical paths of large aperture, J. Opt. Soc. Am., 32, 285-288, 1942.

White, J.: Very Long Optical Paths in Air, J. Opt. Soc. Am., 66, 411-416, 1976.

Wu, C. H. and Niki, H.: Methods for measuring nitrogen dioxide photodissociation rate. Application to smog chamber studies, Environ. Sci. Technol., 9, 46-52, 1975.

Zador, J., Wagner, V., Wirtz, K., and Pilling, M. J.: Quantitative assessment of uncertainties for a model of tropospheric ethene oxidation using the European Photoreactor (EUPHORE), Atmos. Environ., 39, 2805-2817, 2005. 